\title{
Measuring social origin, cognitive ability and educational attainment in the Longitudinal Study of Young People in England (LSYPE)
}

Mollie Bourne ${ }^{1}$, Bastian A. Betthäuser ${ }^{2,3}$, Erzsébet Bukodi ${ }^{1,2}$

\footnotetext{
${ }^{1}$ EngineeringUK, London

2 Nuffield College, Oxford

${ }^{3}$ Department of Social Policy and Intervention, University of Oxford
} 


\section{Contents}

1 Introduction

2 The Longitudinal Study of Young People in England

2.1 Sampling

2.2 LSYPE Data Used for Variable Construction

3 Parental Social Class

4 Parental Social Status

5 Parental Education

6 Parental Income

7 Associations between Social Origin Measures

8 Educational Attainment

9 Cognitive Ability

10 Social Origins and Cognitive Ability

11 Social Origins and Educational Attainment

12 Cognitive Ability and Educational Attainment

Appendix

Acknowledgements: The authors are grateful to the Centre for Longitudinal Studies (CLS), UCL Institute of Education, for the use of the data used and to the UK Data Service for making them available. The research for this Data Note was supported by the Nuffield Foundation (EDU/42195) and the Economic and Social Research Council (ESRC Grant ES/J500112/1). Neither CLS, the UK Data Service the Nuffield Foundation or the ESRC bear any responsibility for the work presented in this Data Note.

The Nuffield Foundation is an independent charitable trust with a mission to advance social well-being. It funds research that informs social policy, primarily in Education, Welfare, and Justice. It also funds student programmes that provide opportunities for young people to develop skills in quantitative and qualitative methods. The Nuffield Foundation is the founder and co-funder of the Nuffield Council on Bioethics and the Ada Lovelace Institute. The Foundation has funded this project, but the views expressed are those of the authors and not necessarily the Foundation. Visit www.nuffieldfoundation.org.

The Economic and Social Research Council ESRC is part of UK Research and Innovation (UKRI), a new organisation that brings together the UK's seven research councils, Innovate UK and Research England to maximise the contribution of each council and create the best environment for research and innovation to flourish. The vision is to ensure the UK maintains its world-leading position in research and innovation.

Data Availability Statement: The data that support the work presented in this Data Note are available from the UK Data Archive. Restrictions apply to the availability of these data, which were used under license for this study. Data are available at http://doi.org/10.5255/UKDA-SN-7104-4 with the permission of the UK Data Archive. 


\section{List of Tables}

Table 1. LSYPE Sample Size across Waves

Table 2. LSYPE Sample Size for Analysis

Table 3. Distribution of Mothers' and Fathers' Social Class (Reduced Method)

Table 4. Cross-tabulation of Mothers' and Fathers' Social Class (Reduced Method)

Table 5. Distribution of Mothers', Fathers' and Parents' CG Social Status Scores (Quartiles)

Table 6. Distribution of Mothers', Fathers' and Parents' CAMSIS Social Status Scores (Quartiles)

Table 7. Pearson's Correlations: Mothers', Fathers' and Parental Social Status Scores (CG and CAMSIS)

Table 8. Distribution of Parental Education (Dominance Approach)

Table 9. Spearman Rank Correlations between the Different Approaches to Creating Parental Education Measure

Table 10. Parental Education (Combined Approach 2): Relative Scale

Table 11. Distribution of Parental Income (Quartiles)

Table 12. Mean CG Status Scores by Parental Class

Table 13. One-way ANOVA: Parental Status by Parental Class

Table 14. Mean Parental Education (7-level Relative Scale, Normalised) by Parental Class

Table 15. One-way ANOVA: Parental Education by Parental Class

Table 16. Cross-tabulation of CG Parental Status Quartiles and Parental Education (Combined Approach 2)

Table 17. Parental Income by Parental Class, CG Status Quartiles and Education (Combined Approach 2)

Table 18. Spearman Rank Correlations: Parental Class, CG Status Quartiles, Education (Combined Approach 2) and Income Quartiles

Table 19. Pearson Correlations: Parental Class, CG Status (Original Scale), Education (Combined Approach 2 and Relative Scale) and Income (Original Scale)

Table 20. Highest Educational Qualification at Age 19-20

Table 21. Transition to Key Stage 5

Table 22. Transition to Key Stage 5 (Academic), Participation v Sitting Exam

Table 23. Highest Educational Qualification Age 19-20 by Transition to Key Stage 5 (Academic)

Table 24. Highest Educational Qualification Age 19-20 by Transition to Key Stage 5 (Academic and Vocational)

Table 25. Transition to Higher Education and Type of Study

Table 26. Transition to Higher Education and Prestige of Institution

Table 27. Cross-tabulation of Highest Educational Qualification Age 19-20 by Transition to Higher Education

Table 28. Cross-tabulation of Highest Educational Qualification Age 19-20 by Transition to Higher Education (Prestige)

Table 29. Transition to Key Stage 5 (Academic) by Transition to Higher Education

Table 30. Transition to Key Stage 5 (Academic and Vocational) by Transition to Higher Education

Table 31. Detailed Activity by Academic Year

Table 32. Cross-tabulation of Detailed Activity and Highest Educational Attainment Age 19-20

Table 33. Performance at Lower Secondary Level

Table 34. Performance at Upper Secondary Level (Respondents who Transitioned to Academic Key Stage 5)

Table 35. Performance at Upper Secondary Level (Full Sample)

Table 36. PCA to Derive Cognitive Ability Measures

Table 37. Mean Cognitive Ability by Parental Class

Table 38. Mean Cognitive Ability by Parental Social Status Quintiles

Table 39. Mean Cognitive Ability by Parental Education

Table 40. Mean Cognitive Ability by Parental Income 
Table 41. Cross-tabulation of Parental Class by Young Person's Educational Attainment (\%)

Table 42. Transition to Key Stage 5 (Academic) and HE by Social Class

Table 43. Cross-tabulation of Parental Education by Young Person's Educational Attainment

Table 44. Transition to Key Stage 5 (Academic) and HE by Parental Education

Table 45. Cross-tabulation of Parental Status Quintiles by Young Person's Educational Attainment (\%)

Table 46. Transition to Key Stage 5 (Academic) and HE by Parental Status Quintiles

Table 47. Cross-tabulation of Parental Income Quintiles by Young Person's Educational Attainment $(\%)$

Table 48. Transition to Key Stage 5 (Academic) and HE by Parental Income Quintiles (\%)

Table 49. Mean Cognitive Ability by Educational Attainment

Table 50. Mean Cognitive Ability by Educational Attainment Thresholds at Age 20

Table 51. Mean Cognitive Ability by Educational Transitions

Table A1. Details on Recoding of Original Parental Education Variables to Bukodi and Goldthorpe (2013) Scale

Table A2. Cross-tabulation between Parental Social Class and Parental Education (Combined Approach 2)

\section{List of Figures}

Figure 1. Distribution of Parental Social Class (Reduced Method)

Figure 2. Boxplot Distribution of Mothers' and Fathers' CG Status Scores (Normalised)

Figure 3. Boxplot Distribution of Mothers' and Fathers' CAMSIS Status Scores

(Normalised)

Figure 4. Distribution of Parental Education (Combined Approaches 1 and 2)

Figure 5. Histogram of Log Weekly Gross Parental Income

Figure 6. Boxplot Distribution of Parental CG Status Scores by Parental Class

Figure 7. Boxplot Distribution of Parental Education (7-level Relative Scale, Normalised) by Parental Class

Figure 8. Proportion of Cases: (i) Neither Parent has Any Qualification, and (ii) Both Parents have Degree-level Qualifications, by Parental Class

Figure 9. Boxplot Distribution of Parental CG Status Scores (Original Scale) by Parental Education (Combined Approach 2)

Figure 10. Performance at Lower Secondary Level - Number of GCSE/GNVQ Qualifications at Grades A*-C

Figure 11. Performance at Upper Secondary Level (for Respondents who Made Transition to Key Stage 5) - Number of A-levels Passed

Figure 12. Histogram of Cognitive Ability Measures

Figure 13. Boxplot Distribution of Cognitive Ability (KS2em) by Parental Class

Figure 14. Boxplot Distribution of Cognitive Ability (KS2emX2) by Parental Class

Figure 15. Boxplot Distribution of Cognitive Ability (KS2em) by Parental Social Status Quintiles

Figure 16. Boxplot Distribution of Cognitive Ability (KS2emX2) by Parental Social Status Quintiles 


\section{$1 \quad$ Introduction}

This data note has been prepared for the Social Origins, Cognitive Ability and Educational Attainment: A birth Cohort and Life-Course Perspective project. The document will describe the construction of variables using data from the Longitudinal Study of Young People in England (LSYPE) 4 . Specifically, it will provide information on the focal independent variables which will be used in analysis - parental education, class, status and income, and respondents' early-life cognitive ability - as well as the dependent variable(s) of educational attainment, as recorded in the National Pupil Database (NPD). The purpose of the data note is to carefully document the preparatoy work undertaken, in the interests of replicability and transparency, and to provide a clear basis for comparison with the approach taken to the construction of similar variables in other datasets used in the project. The distributions of each constructed measure are presented, as well as descriptive analyses of the associations that exist between them.

Section 2 will provide a brief introduction to the LSYPE dataset. Sections 3-6 will examine each of the dimensions of social origin in turn, and Section 7 will describe the relationships between them. Section 8 details the educational attainment outcome variables. Section 9 explains the construction of two measures of cognitive ability. Sections 10 and 11 then present associations between social origin and educational attainment and social origin and cognitive ability, respectively. Finally, Section 12 examines the relationship between cognitive ability and educational attainment.

\section{The Longitudinal Study of Young People in England}

The LSYPE is a large-scale panel study following a sample of young adults in England who were born between 1 September 1989 and 31 August 1990. The original sample comprised over 33,000 young people in Year 9 in February 2004, aged between 13-14 years. The survey gathers information from questionnaires with both parents and children, administered annually. Seven waves of data are currently available, with the latest wave therefore providing information on the young people at 19-20 years of age. The survey provides information on a 'variety of influences on learning and progression' (LSYPE User Guide); with relevance to this project, included in the dataset is detailed information on respondents' home circumstances, including parental class, educational qualifications and other resources, personal characteristics such as ethnicity and gender, employment/educational status at various stages in the life course and, through linked administrative data, the LSYPE also documents the young people's attainment of formal educational qualifications.

\subsection{Sampling}

The LSYPE used a multi-stage stratified sampling design. Schools (independent, maintained and pupil referral units), drawn from the Pupil Annual School Leaving Census and the School Level Annual School Census, were used as the primary sampling units (PSUs). ${ }^{5}$ Maintained schools were stratified into deprived/non-deprived, with the latter over sampled. Stage two involved sampling pupils from within each of these PSUs (on average, 33 pupils were sampled per school). Pupils from major minority ethnic groups were over sampled and a sample boost included the $20 \%$ of schools with the most pupils in receipt of free school meals (FSM). A further ethnic minority boost sample was introduced at wave 4 (this consisted of an achieved sample of 352 cases - a 59\% response rate). At the school level, the LSYPE

\footnotetext{
${ }^{4}$ University College London, UCL Institute of Education, Centre for Longitudinal Studies (2018). Next Steps: Sweeps 1-8, 2004-2016: Secure Access. [data collection]. 4th Edition. UK Data Service. SN: 7104, http://doi.org/10.5255/UKDA-SN-7104-4

${ }^{5}$ Children educated solely at home, pupils in schools with fewer than 10 (maintained sector) or 6 (independent sector) Year 9 pupils, boarders, and those residing in the UK only for education purposes were excluded from sampling.
} 
achieved a $73 \%$ response rate (with 647 of 892 sampled schools participating in the study). At the individual level, the study achieved a $74 \%$ response rate, resulting in an achieved sample of 15,770 participants. This figure reduced over subsequent waves due to attrition. See Table 1.

Table 1. LSYPE Sample Size across Waves

\begin{tabular}{ccccccc}
\hline Wave 1 & Wave 2 & Wave 3 & Wave 4 & Wave 5 & Wave 6 & Wave 7 \\
\hline 15,770 & 13,539 & 12,439 & 11,801 & 10,430 & 9,799 & 8,682 \\
\hline
\end{tabular}

\subsection{LSYPE Data Used for Variable Construction}

Information used to construct social origin variables is taken from wave 2 of the survey, when cohort members were between 14-15 years old. ${ }^{6}$ This decision is taken because it is at wave 2 that the most detailed information on the key social origin variables is available. However, in attempts to maximise the number of valid cases, variables are supplemented with information at wave 1 for those with item or unit missing data at wave 2; the details of precisely how this is done are given in each relevant section.

The LSYPE provides information on 'main parents' and 'second parents', with the former defined as the person most involved in the cohort member's education and the latter defined as the partner or spouse of the main parent. In the majority of cases, the main parent is the natural mother of the cohort member; however this can change across waves. Tables in this document which provide information for 'mothers' refer to female parents and those which provide information for 'fathers' refer to male parents.

Variables are described in this data note using the final sample size; i.e. the sample after all cases with missing information on the outcome variable or any of the focal independent variables have been dropped. This includes those with missing information on the Key Stage 2 variable, which is taken to represent cognitive ability at age 11 , but does not include those with missing information on parental income because this will only be used in supplementary analyses. The initial sample size was 16,122 (comprised of the 15,770 original respondents who participated at wave 1 and the 352 boost cases introduced at wave 4), which is reduced to a final sample size of 7,668 (48\%) once all exclusions have been made. This project requires information on educational attainment from respondents at the latest available wave, and the majority of missing cases are therefore due to sample attrition. See Table 2 for more detail.

Table 2. LSYPE Sample Size for Analysis

\begin{tabular}{|c|c|c|c|}
\hline & Missing $\mathbf{N}$ & Remaining $\mathbf{N}$ & $\%$ \\
\hline Overall LSYPE Sample & & 16122 & 100 \\
\hline Respondents in Wave 7 & -7440 & 8682 & 53.85 \\
\hline Respondents in NPD KS2-4 file: & -188 & 8494 & 52.29 \\
\hline KS2 Performance & -525 & 7969 & 49.43 \\
\hline Highest qualification at age 20 & 0 & 7969 & 49.43 \\
\hline Parental class & -301 & 7668 & 47.56 \\
\hline Parental status & 0 & 7668 & 47.56 \\
\hline Parental education & 0 & 7668 & 47.56 \\
\hline Total $†$ & 8454 & 7668 & 47.56 \\
\hline \multicolumn{4}{|l|}{ Notes: $\quad$ 'Wave 1 sample + wave 4 boost } \\
\hline \multicolumn{4}{|c|}{$\begin{array}{l}\ddagger \text { The number of missing cases listed here is based on the Key Stage } 2 \text { average points score variable. A further } 83 \text { cases are missing on } \\
\text { the 'KS2em' cognitive ability measure and a further } 155 \text { on the 'KS2emX2' measure } \\
+1647 \text { further cases are missing information on parental income, reducing the final sample size to } \\
6021 \text { for analyses involving this measure }\end{array}$} \\
\hline
\end{tabular}

\footnotetext{
${ }^{6}$ For parental income, information is primarily taken from wave 1.
} 
Note that all frequencies (denoted $\mathrm{N}$ ) are unweighted, while all percentages and other statistics account for the multi-stage stratified sampling design of the LSYPE as well as non-response, using Stata's svyset command.

\section{$3 \quad$ Parental Social Class}

The construction of the parental social-class variable first involved allocating SOC2000 codes to mothers and fathers. At wave 2, a four-digit occupational unit code is given for both parents, though at wave 1 only major SOC code (one-digit) information is available. For each major SOC code, the modal corresponding unit code at wave 2 was derived and cases were assigned this value for wave 1 . Those cases which then had missing information at wave 2 (this includes those listed as long-term unemployed and those who have never worked) were given a SOC2000 code from wave 1. Information on the gender of main and second parents was then used to determine the SOC2000 codes for mothers and fathers.

Using NS-SEC conversion tables, this information was then employed to assign each parent a class using the simplified method. Subsequently, employment status information was used to determine a class for each parent using the reduced method. Missing cases retained their simplified NS-SEC class. See Table 3 which displays the distribution of social class for mothers and fathers using the reduced method.

Table 3. Distribution of Mothers' and Fathers' Social Class (Reduced Method)

\begin{tabular}{lcccc}
\hline & \multicolumn{2}{c}{ Mothers } & \multicolumn{2}{c}{ Fathers } \\
\cline { 2 - 5 } 1. Higher managerial & $\mathbf{\%}$ & $\mathbf{N}$ & $\mathbf{\%}$ & $\mathbf{N}$ \\
\cline { 2 - 5 } 2. Lower managerial & 5 & 371 & 18 & 1119 \\
3. Intermediate & 28 & 2037 & 24 & 1458 \\
4. Small employers & 16 & 1176 & 4 & 269 \\
5. Lower supervisory & 5 & 345 & 13 & 783 \\
6. Semi-routine & 9 & 568 & 17 & 931 \\
7. Routine & 24 & 1581 & 10 & 618 \\
Missing & 13 & 866 & 14 & 877 \\
Total & & 724 & & 1613 \\
& 100 & 7668 & 100 & 7668 \\
\hline
\end{tabular}

Table 4 compares mothers' and fathers' NS-SEC classes in a cross-tabulation. Classes $3-5$ were collapsed for this table in order to yield an ordinal classification. Mothers are found to reach a higher social class than fathers in $41 \%$ of cases $(n=2882)$, fathers reach a higher class in $37 \%$ of cases $(n=3077)$ and in $22 \%$ of cases $(n=1709)$ mothers and fathers belong to the same social class.

Table 4. Cross-tabulation of Mothers' and Fathers' Social Class (Reduced Method)

\begin{tabular}{|c|c|c|c|c|c|c|c|}
\hline & \multicolumn{6}{|c|}{ Fathers } \\
\hline & & Higher man & Lower man & Intermediate & Semi routine & Routine & Total \\
\hline \multirow{15}{*}{$\begin{array}{l}\frac{\infty}{0} \\
\frac{d}{0} \\
\frac{0}{\Sigma}\end{array}$} & Higher & 152 & 80 & 55 & 7 & 11 & 305 \\
\hline & managerial & $48 \%$ & $29 \%$ & $18 \%$ & $2 \%$ & $3 \%$ & $100 \%$ \\
\hline & & $13 \%$ & $6 \%$ & $3 \%$ & $1 \%$ & $1 \%$ & $5 \%$ \\
\hline & Lower & 400 & 557 & 443 & 85 & 115 & 1600 \\
\hline & managerial & $25 \%$ & $33 \%$ & $28 \%$ & $6 \%$ & $8 \%$ & $100 \%$ \\
\hline & & $38 \%$ & $39 \%$ & $25 \%$ & $18 \%$ & $17 \%$ & $30 \%$ \\
\hline & Intermediate & 285 & 414 & 635 & 118 & 175 & 1627 \\
\hline & & $17 \%$ & $24 \%$ & $41 \%$ & $6 \%$ & $12 \%$ & $100 \%$ \\
\hline & & $26 \%$ & $30 \%$ & $38 \%$ & $22 \%$ & $28 \%$ & $31 \%$ \\
\hline & Semi routine & 203 & 243 & 391 & 166 & 180 & 1183 \\
\hline & & $16 \%$ & $20 \%$ & $34 \%$ & $14 \%$ & $16 \%$ & $100 \%$ \\
\hline & & $19 \%$ & $19 \%$ & $23 \%$ & $36 \%$ & $28 \%$ & $23 \%$ \\
\hline & Routine & 39 & 67 & 207 & 104 & 199 & 616 \\
\hline & & $7 \%$ & $12 \%$ & $34 \%$ & $17 \%$ & $30 \%$ & $100 \%$ \\
\hline & & $4 \%$ & $6 \%$ & $12 \%$ & $22 \%$ & $26 \%$ & $11 \%$ \\
\hline
\end{tabular}




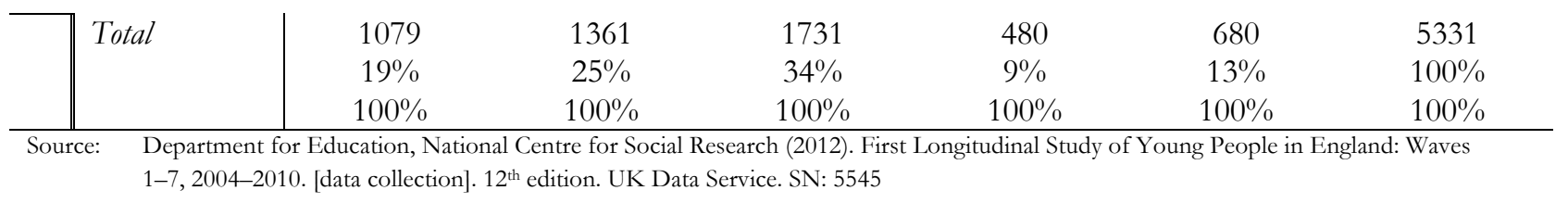

The dominance approach was then used to construct the parental social-class measure. Following Bukodi and Goldthorpe (2013), 'the class of a parent in full-time work dominates that of a parent in part-time work, and where parents are both in full or part-time work, husband's class is taken to dominate wife's class unless the latter is higher in the ordering of the classes as $1,2,3-5,6,7$, in which case wife's class dominates' (2013: 14). Figure 1 illustrates the distribution of the parental social-class variable.

Figure 1. Distribution of Parental Social Class (Reduced Method)

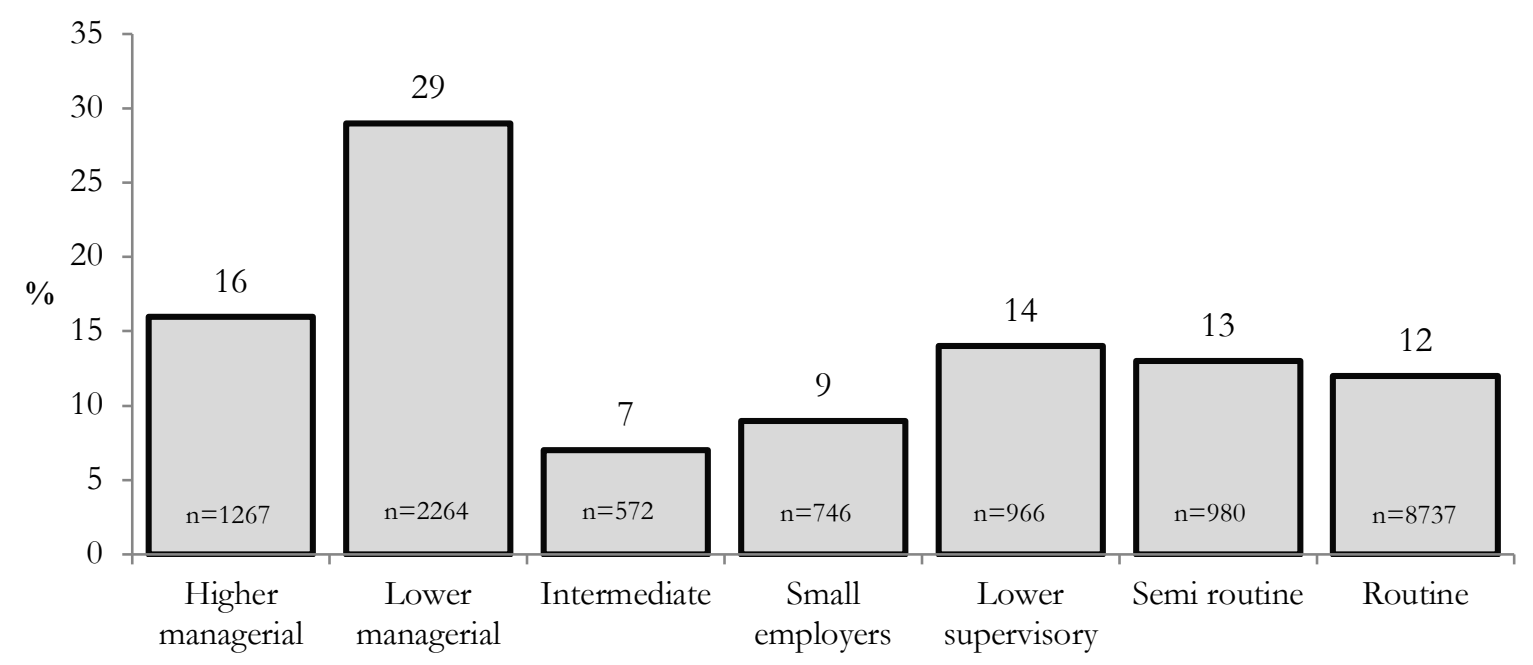

\section{$4 \quad$ Parental Social Status}

Two measures of parental status have been constructed. The first is based on the Chan-Goldthorpe (CG) status order (Chan and Goldthorpe 2004). Mothers' and fathers' SOC2000 codes were first converted to SOC90 codes which are required for the CG scale, ${ }^{7}$ and status scores were subsequently derived using the conversion table. ${ }^{8}$ Figure 2 illustrates the distribution of mothers' and fathers' CG status scores which have been normalised so that cases take a value between $0-1$.

Figure 2. Boxplot Distribution of Mothers' and Fathers' CG Status Scores (Normalised)

\footnotetext{
748 fathers and 114 mothers had SOC2000 codes which did not have a corresponding SOC90 code (these classifications did not exist in earlier versions of the SOC). These cases were given a value based on the modal SOC90 code for that SOC2000 category.

827 fathers and 4 mothers had SOC90 codes of 119 or 166 which do not feature in the CG conversion table. These cases were given a status score for the corresponding SOC2000 category (or NS-SEC category where this was not possible).
} 


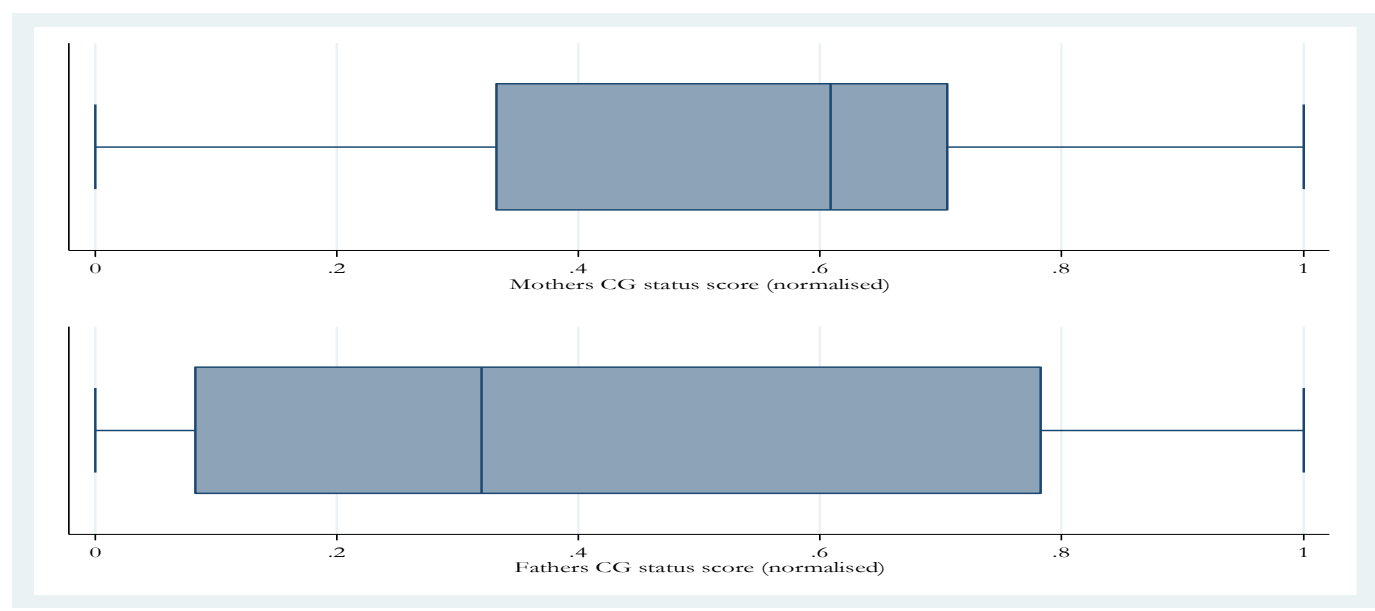

Notes: Graphs use the wave 7 probability weight provided in the LSYPE dataset: W7_lsype_wt_skip Mother variable $\mathrm{N}=6944$; Father variable $\mathrm{N}=6055$

Mothers' mean (normalised) CG status score is 0.55 compared with fathers' mean score of 0.43 .

Therefore, similar to what is shown above for social class, mothers tend to occupy a slightly higher social position than fathers. Table 5 presents the frequencies of mothers' and fathers' CG social status scores with the original interval-scale variable having been grouped into quartiles.

A parental social status variable was then constructed by taking the highest status score between the mother and the father. In instances where one was missing, the valid score was assigned. The quartiles for this variable are also given in Table 5 . When this measure is normalised with range $0-1$, the mean score is 0.58 with standard deviation 0.28 .

Table 5. Distribution of Mothers', Fathers' and Parents' CG Social Status Scores (Quartiles)

\begin{tabular}{|c|c|c|c|c|c|c|}
\hline & \multicolumn{2}{|c|}{ Mothers' Status } & \multicolumn{2}{|c|}{ Fathers' Status } & \multicolumn{2}{|c|}{ Parents' Status } \\
\hline & \%\% & $\mathrm{N}$ & 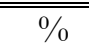 & $\overline{\mathrm{N}}$ & \%\% & $\overline{\mathrm{N}}$ \\
\hline $1^{\text {st }}$ Quartile & 30 & 1933 & 34 & 1975 & 27 & 2055 \\
\hline $2^{\text {nd }}$ Quartile & 26 & 1821 & 18 & 1121 & 28 & 2040 \\
\hline $3^{\text {rd }}$ Quartile & 24 & 1738 & 25 & 1574 & 23 & 1775 \\
\hline $4^{\text {th }}$ Quartile & 20 & 1452 & 23 & 1385 & 22 & 1798 \\
\hline Missing & & 724 & & 1613 & & \\
\hline Total & 100 & 7668 & 100 & 7668 & 100 & 7668 \\
\hline
\end{tabular}

The second parental status variable is based on the CAMSIS scale. This provides two separate scales for men and women, assuming that social hierarchies vary according to gender. ${ }^{9}$ Figure 3 illustrates the distribution of mothers' and fathers' CAMSIS scores which have again been normalised so that the range is $0-1$ for both variables. Mothers' mean (normalised) CAMSIS score is 0.42 compared with fathers' mean score of 0.47 . Using this alternative measure, therefore, fathers are found to tend to occupy higher social positions than mothers.

Figure 3. Boxplot Distribution of Mothers' and Fathers' CAMSIS Status Scores (Normalised)

\footnotetext{
${ }^{9}$ SOC90 scores were used instead of SOC2000 scores for consistency with the approach taken to generating CG scores and also because a version of CAMSIS has not been created using the SOC2000 codes.
} 

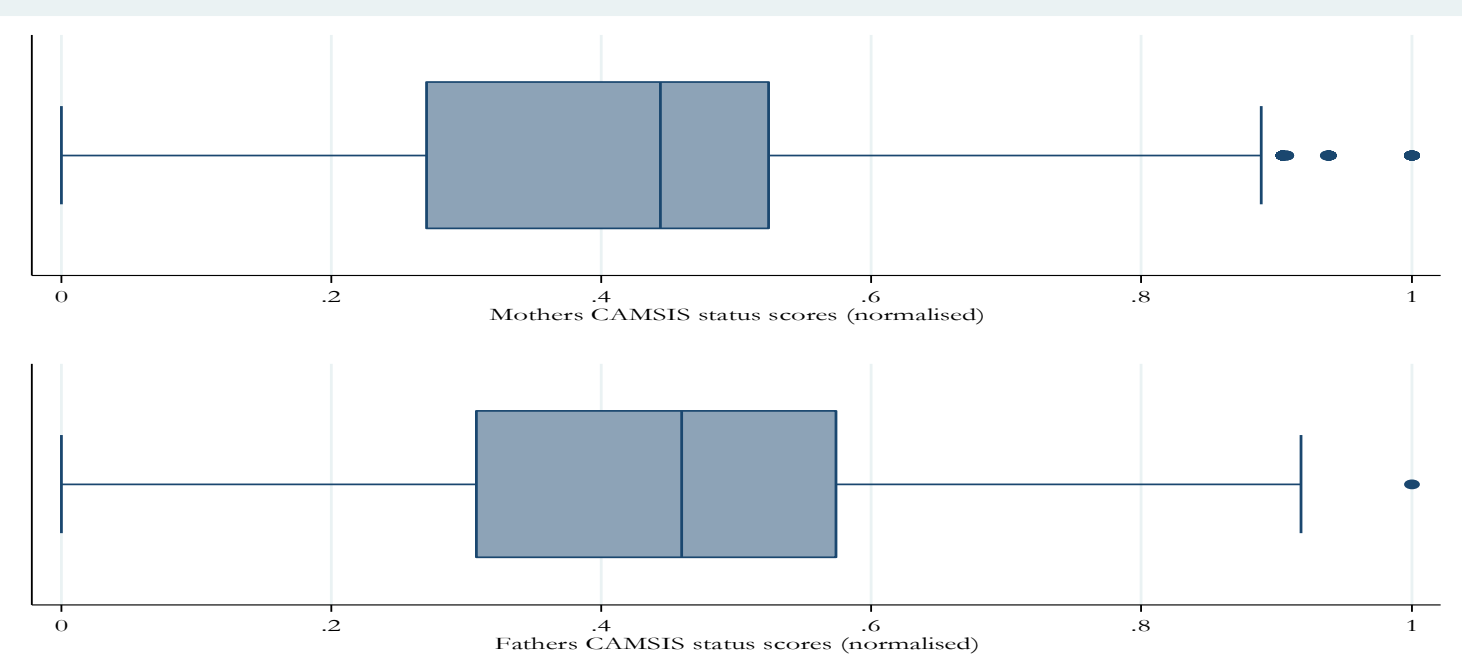

Notes: Graphs use the wave 7 probability weight provided in the LSYPE dataset: W7_lsype_wt_skip Mother variable $\mathrm{N}=6944$; Father variable $\mathrm{N}=6055$

Table 6 presents quartiles and frequencies taken from the original interval-scale variables, and also gives parental CAMSIS status which has been derived using the dominance approach. When this parental variable is normalised with range $0-1$, the mean score is 0.51 with standard deviation 0.17 .

Table 6. Distribution of Mothers', Fathers' and Parents' CAMSIS Social Status Scores (Quartiles)

\begin{tabular}{|c|c|c|c|c|c|c|}
\hline & \multicolumn{2}{|c|}{ Mothers' Status } & \multicolumn{2}{|c|}{ Fathers' Status } & \multicolumn{2}{|c|}{ Parents' Status } \\
\hline & "\% & $\overline{\mathrm{N}}$ & \%\% & $\overline{\mathrm{N}}$ & \%\% & $\overline{\mathrm{N}}$ \\
\hline $1^{\text {st }}$ Quartile & 28 & 1773 & 27 & 1523 & 27 & 1994 \\
\hline $2^{\text {nd }}$ Quartile & 26 & 1820 & 24 & 1510 & 25 & 1860 \\
\hline $3^{\text {rd }}$ Quartile & 25 & 1814 & 25 & 1518 & 25 & 1898 \\
\hline $4^{\text {th }}$ Quartile & 21 & 1537 & 24 & 1504 & 24 & 1916 \\
\hline Missing & & 724 & & 1613 & & \\
\hline Total & 100 & 7668 & 100 & 7668 & 100 & 7668 \\
\hline
\end{tabular}

Table 7 presents Pearsons' correlations between the various measures of the CG and CAMSIS scale variables described above. These correlations are based on the original interval-scale variables.

Table 7. Pearsons' Correlations: Mothers', Fathers' and Parental Status Scores (CG and CAMSIS)

\begin{tabular}{|c|c|c|c|c|c|}
\hline & Mother (CG) & Mother (CAM) & \multirow{3}{*}{$\begin{array}{l}\text { Father (CG) } \\
\text { Father (CAM) }\end{array}$} & Father (CG) & Father (CAM) \\
\hline Mother (CG) & 1.00 & & & 1.00 & \\
\hline \multirow{2}{*}{ Mother (CAM) } & $0.88^{* *}$ & 1.00 & & $0.88^{* *}$ & 1.00 \\
\hline & Mother (CG) & Father (CG) & \multirow{6}{*}{$\begin{array}{l}\text { Mother (CAM) } \\
\text { Father (CAM) }\end{array}$} & Mother (CAM) & Father (CAM) \\
\hline Mother (CG) & 1.00 & & & 1.00 & \\
\hline \multirow[t]{2}{*}{ Father (CG) } & $0.37 * *$ & 1.00 & & $0.41 * *$ & 1.00 \\
\hline & Parents (CG) & Parents (CAM) & & & \\
\hline Parents (CG) & 1.00 & & & & \\
\hline Parents (CAM) & $0.88^{* *}$ & 1.00 & & & \\
\hline
\end{tabular}

\section{$5 \quad$ Parental Education}

Parental education variables were created using information from main and second parents, as opposed to mothers and fathers, because the latter approach also requires information on gender which results in 
more cases with missing information. Parents' gender is not required for the dominance approach when applied to parental education, nor the alternative combined approaches (described below).

The 'detailed qualifications' variables given in the dataset are used, which provide the most fine-grained information available. The information was taken from wave 2, but replaced with information from wave 1 where any cases had missing data. The variables were recoded according to the eight ${ }^{10}$ ordered categories given in Bukodi and Goldthorpe (2013); details on precisely how the qualifications given in the original variable were reallocated to the present categories are given in Table A1 in the Appendix. The distribution of the parental education measure, constructed using the dominance approach, is given in Table 8 .

Table 8. Distribution of Parental Education (Dominance Approach)

1. No qualifications

2. Below O-level, NVQ 1 [sub-secondary)

3. 1-4 O-level passes, NVQ 2 [secondary - low performance)

4. 5+ O-level passes or 1 A-level pass, NVQ 3 [secondary - higher performance]

5. 2+ A-level passes [higher secondary]

6. Tertiary sub-degree qualification, NVQ 4 [lower tertiary]

7. Degree, NVQ 5 [higher tertiary]

8. Higher degree, NVQ6 [higher tertiary]

Total

\begin{tabular}{cc}
$\mathbf{\%}$ & $\mathbf{N}$ \\
\hline \hline 10 & 973 \\
8 & 551 \\
27 & 1889 \\
14 & 962 \\
6 & 458 \\
17 & 1315 \\
12 & 1028 \\
6 & 492 \\
100 & 7668 \\
\hline
\end{tabular}

An alternative is to create a combined parental education variable, reflecting the approach taken by Bukodi and Goldthorpe (2013). Information from both parents is incorporated into this measure and given in the following categories:

1. Neither parent has any qualification

2. One parent has secondary or lower qualification; other parent has no qualification

3. Both parents have secondary or lower qualification

4. One parent has higher secondary or lower tertiary qualification; other parent has lower qualification

5. Both parents have higher secondary or lower tertiary qualification

6. One parent has degree-level qualification; other parent has lower qualification

7. Both parents have degree-level qualifications

However, this method requires a plausible assumption to be made regarding missing values if educational information is only available for one parent. Two strategies are considered: (1) assuming the value of the missing parent is 'no qualification'; and (2) assuming the value of the missing parent is equal to the modal value for partners corresponding to the valid category. The distributions of the variables constructed using these two assumptions are given in Figure 4.

Figure 4. Distribution of Parental Education (Combined Approaches 1 and 2)

${ }^{10}$ Bukodi and Goldthorpe (2013) collapse degree and higher degree categories due to a lack of detail in the data used. 


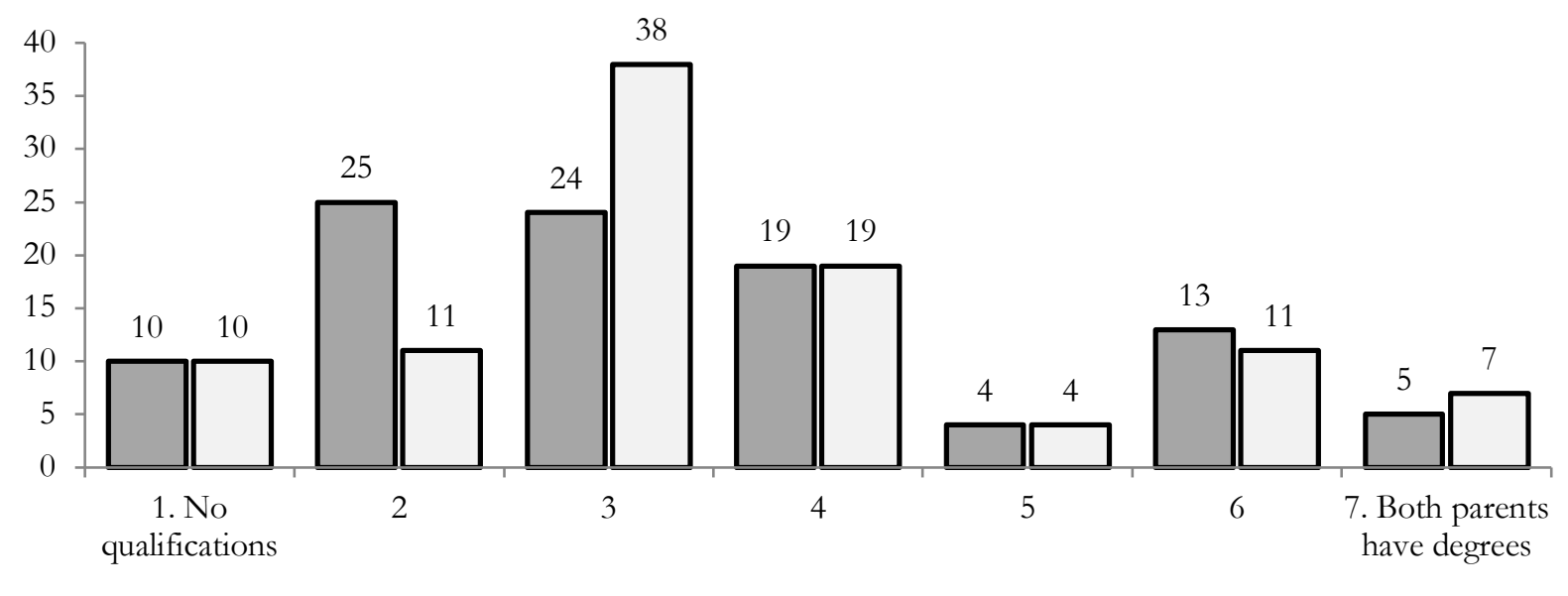

$\boldsymbol{\square}(1)$ Missing $=$ No qualifications $\boldsymbol{\square}(2)$ Missing $=$ Modal corresponding value

Table 9 shows that the Spearman rank correlations between the different approaches to combining the main and second parents' educational information are very high.

Table 9. Spearman Rank Correlations between the Different Approaches to Creating Parental Education Measure

\begin{tabular}{lccc}
\hline & Dominance approach & Combined approach 1 & Combined approach 2 \\
\cline { 2 - 4 } Dominance approach & 1.00 & & \\
Combined approach 1 & $0.94^{* *}$ & 1.00 & 1.00 \\
Combined approach 2 & $0.94^{* *}$ & $0.97^{* *}$ & \\
\hline
\end{tabular}

Notes: Weights are not permitted with the Spearman command in Stata

For the remainder of this data note, the combined approach which replaces information on missing parents with the modal corresponding value (combined approach 2) is used to represent parental education. Finally, to treat education in relative terms and to therefore facilitate cross-cohort comparisons, scores can be assigned to each category according to the percentage of parents falling below that level in the cumulative distribution (Bukodi and Goldthorpe 2013). Table 10 presents the distribution of this relative scale.

Table 10. Parental Education (Combined Approach 2): Relative Scale

\begin{tabular}{lr}
\hline & \% falling below educational level \\
\hline & 0.00 \\
3 & 10.18 \\
4 & 21.26 \\
5 & 59.36 \\
6 & 77.91 \\
7 & 82.30 \\
Mean level (0-1) & 92.89 \\
Standard deviation (0-1) & 0.400 \\
\hline Source: $\quad$ Department for Education, National Centre for Social Research (2012). First Longitudinal Study of Young People in England: Waves \\
$\quad 1-7,2004-2010$. [data collection]. 12th
\end{tabular}

The mean educational level is calculated by normalising the relative scale variable so that values are within the range 0-1. It should be compared to those given by Bukodi and Goldthorpe (2013) for the earlier cohorts:

1946 cohort: $\quad$ Mean 0.306 , Standard deviation 0.371

1958 cohort: $\quad$ Mean 0.363 , Standard deviation 0.340

1970 cohort: $\quad$ Mean 0.389 , Standard deviation 0.326 


\section{$6 \quad$ Parental Income}

The parental income variable described in this section measures the total income from work, benefits and anything else from the main parent and partner. Information is used from wave 1 of the survey, ${ }^{11}$ though cases with missing information are given a value from wave 2 where this is applicable. Two variables are employed: the first asks respondents to report their annual income from a list of 32 bands and the second asks those who selected the highest band (32) to report, from a further list of 60 high-income categories, which band their annual income falls into. These measures were combined, resulting in 91 categories. The upper and lower bounds of each category were then transformed info weekly amounts ( $\mathrm{x} / 52)$, and cases were reassigned an income figure based on the mid-value of their band. The variable is treated as continuous. Of the 7668 cases used in this data note, 1647 are missing information on parental income. Figure 5 illustrates the distribution after $\log$ transforming the values.

Figure 5. Histogram of Log Weekly Gross Parental Income

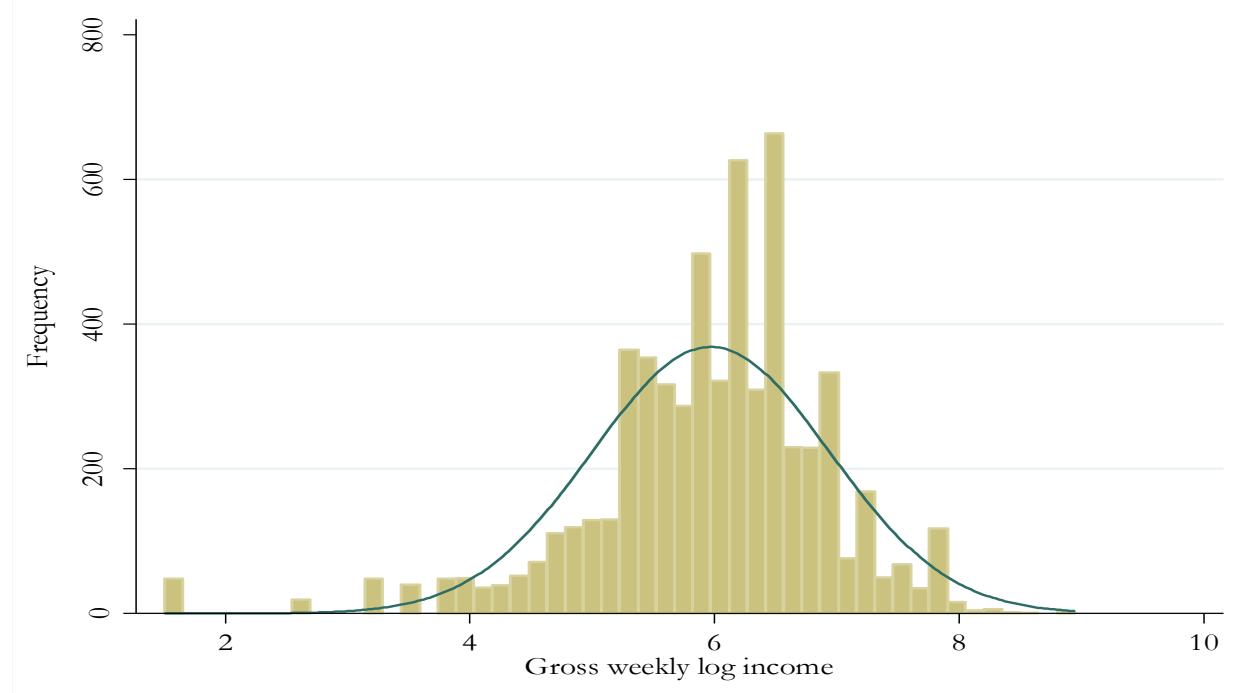

Notes: Only frequency weights are permitted for histograms, so no weights have been applied

This variable has minimum and maximum values of 4.5 and 7693. Mean gross parental income is $f, 567.59$ per week, with standard deviation 540.93. Median gross parental income is $f 424.50$, which is equivalent to an annual combined income of $£ 22,074$. These amounts have been checked against gross weekly household incomes from the 2004/05 year of the Expenditure and Food Survey, which are very similar. ${ }^{12}$ Table 11 gives the distribution of parental income when the original variable is grouped into quartiles.

Table 11. Distribution of Parental Income (Quartiles)

\begin{tabular}{|c|c|c|}
\hline & $\%$ & $\mathbf{N}$ \\
\hline 1 $^{\text {st }}$ Quartile & 28 & 1658 \\
\hline $2^{\text {nd }}$ Quartile & 24 & 1424 \\
\hline $3^{\text {rd }}$ Quartile & 25 & 1485 \\
\hline $4^{\text {th }}$ Quartile & 23 & 1454 \\
\hline Missing & & 1647 \\
\hline Total & 100 & 7668 \\
\hline
\end{tabular}

\footnotetext{
${ }^{11}$ Information is taken from wave 1 because it was at this point all main parents were asked to provide a response. ${ }^{12}$ Using the 2004/05 Expenditure and Food Survey, the mean gross current income of households is $f, 555.52$ with standard deviation 608.99, and median income is $£ 425.60$.
} 


\section{$7 \quad$ Associations between Social Origin Measures}

This section presents the results from a series of bivariate analyses between the social origin measures. First, the parental CG status score variable (original scale) is considered in terms of its distribution across parental social class. See Figure 6 and Table 12.

Figure 6. Boxplot Distribution of Parental CG Status Scores by Parental Class

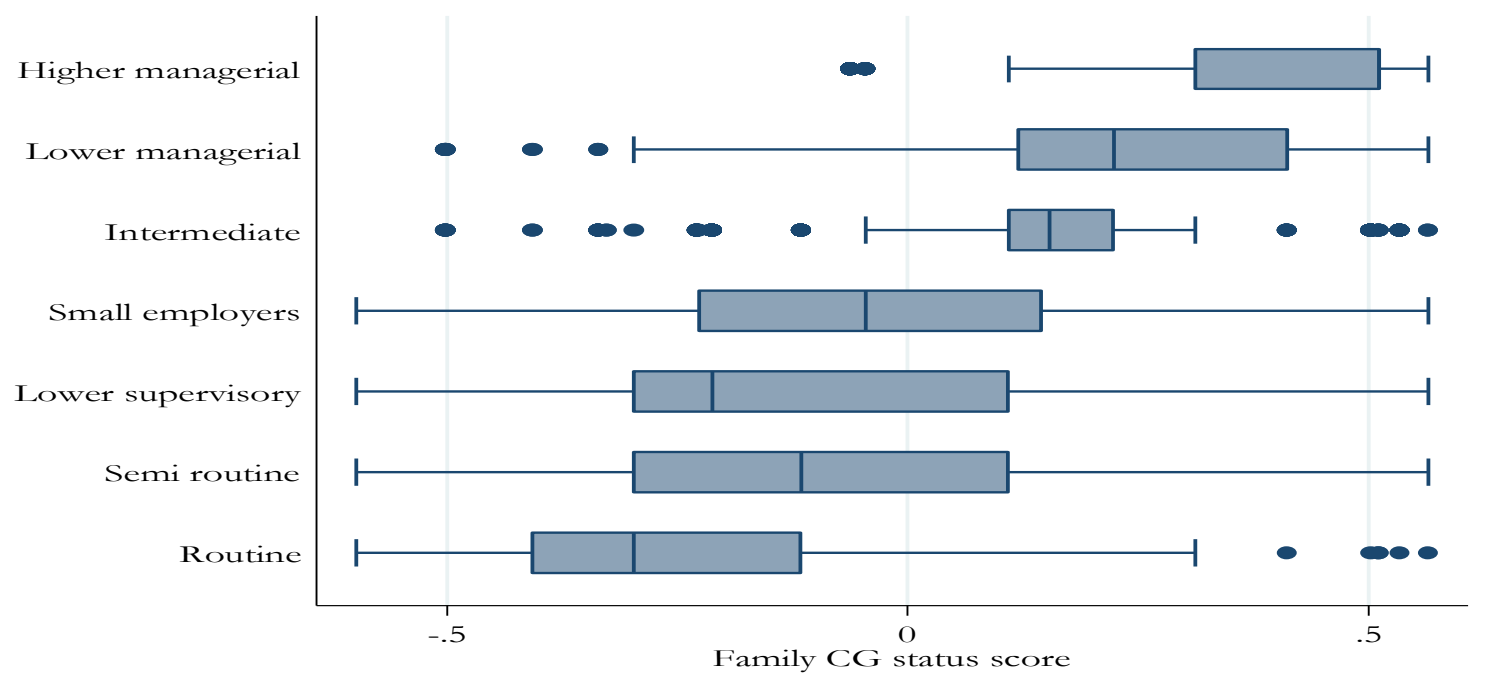

Notes: Graph uses wave 7 probability weight provided in the LSYPE dataset: W7_lsype_wt_skip

Table 12. Mean CG Status Scores by Parental Class

Higher managerial

\begin{tabular}{ccc} 
Mean & SD & $\mathbf{N}$ \\
\hline \hline 0.42 & 0.18 & 1267 \\
0.25 & 0.22 & 2264 \\
0.14 & 0.20 & 572 \\
-0.03 & 0.27 & 746 \\
-0.13 & 0.26 & 966 \\
-0.14 & 0.22 & 980 \\
-0.25 & 0.23 & 873 \\
\hline
\end{tabular}

Lower managerial

Intermediate

Small employers

Lower supervisory

$-0.25$

0.23

873

Routine

Table 13 presents the results of a one-way analysis of variance, showing that differences between groups are statistically significant, and that $52 \%$ of the total variance in parental status is explained by parental class.

Table 13. One-way ANOVA: Parental Status by Parental Class

\begin{tabular}{|c|c|c|c|c|}
\hline Between groups & Within groups & $\mathbf{F}$ & $\mathrm{p}$ & $\%$ \\
\hline 409.02 & 380.93 & 1370.99 & 0.00 & 0.52 \\
\hline
\end{tabular}

Table 14 uses the 7-level relative scale parental education variable (normalised with range 0-1) to present the mean level of parental education for each social-class group. Figure 7 plots this information graphically.

Table 14. Mean Parental Education (7-level Relative Scale, Normalised) by Parental Class

Higher managerial

Lower managerial

Intermediate

Small employers

\begin{tabular}{ccc} 
Mean & SD & $\mathbf{N}$ \\
\hline \hline 0.71 & 0.28 & 1267 \\
0.53 & 0.32 & 2264 \\
0.32 & 0.29 & 572 \\
0.32 & 0.28 & 746 \\
\hline
\end{tabular}




\begin{tabular}{llll}
\hline Lower supervisory & 0.27 & 0.24 & 966 \\
Semi routine & 0.19 & 0.21 & 980 \\
Routine & 0.16 & 0.19 & 873 \\
\hline
\end{tabular}

Figure 7. Boxplot Distribution of Parental Education (7-level Relative Scale, Normalised) by Parental Class

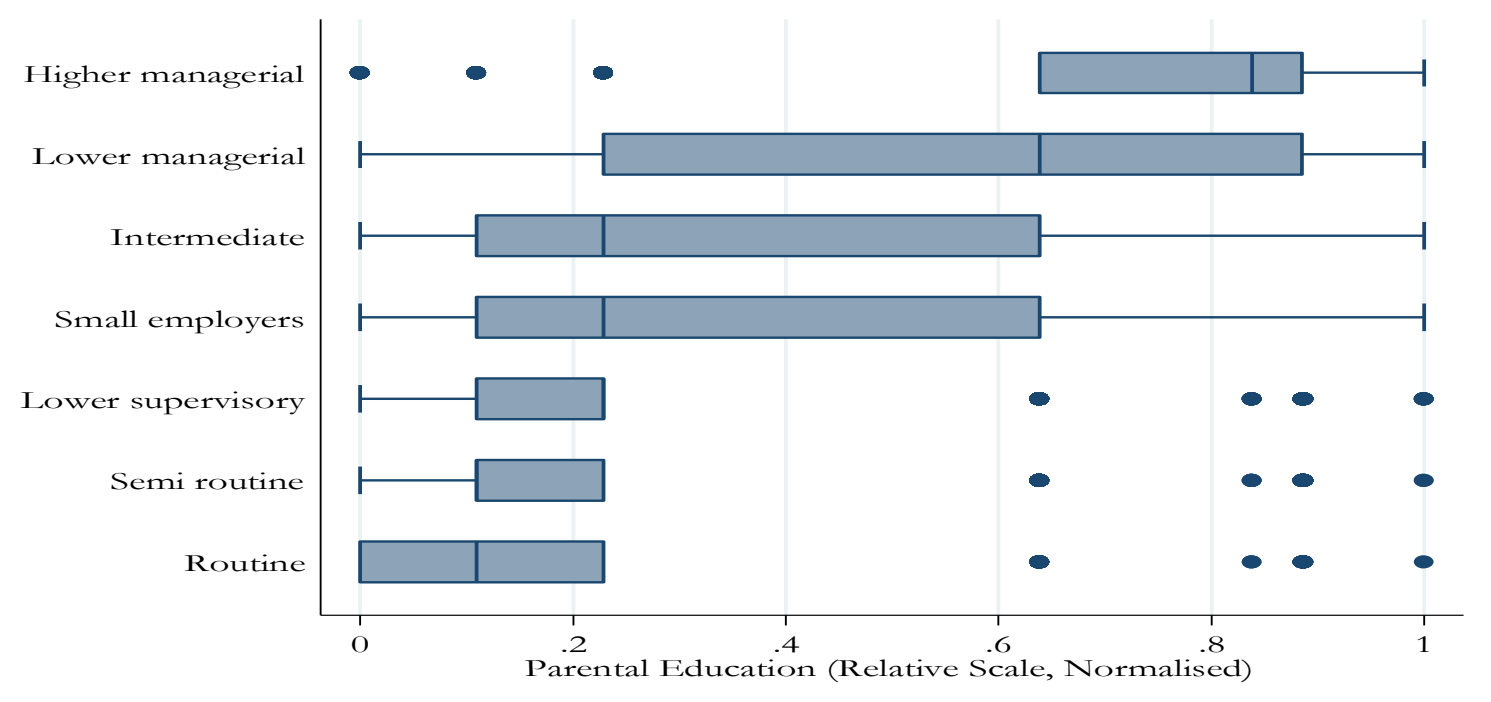

Notes: Graph uses wave 7 probability weight provided in the LSYPE dataset: W7_lsype_wt_skip

Table 15 gives the results of a one-way analysis of variance. Differences in the mean educational level between social classes are statistically significant and 33\% of the total variance in parental education is explained by parental class.

Table 15. One-way ANOVA: Parental Education by Parental Class

\begin{tabular}{|c|c|c|c|c|}
\hline Between groups & Within groups & $\mathbf{F}$ & p & $\%$ \\
\hline 240.05 & 496.49 & 617.35 & 0.00 & 0.33 \\
\hline
\end{tabular}

A cross-tabulation between parental class and education is given in Table A2 in the Appendix which instead uses the categorical parental education variable (combined approach 2). Figure 8 below depicts a crude summary of the relationship by comparing the proportions of cases for which: (i) neither parent has any qualification, and (ii) both parents have degree-level qualifications, by each social-class group. Among those from the higher managerial class, $21 \%$ of cases have two parents with degree-level qualifications, compared with just $1 \%$ or less among those from lower supervisory, semi-routine or routine classes. Conversely, only $1 \%$ of those from higher managerial backgrounds have parents with no qualifications, compared with $31 \%$ of those from the routine class. 
Figure 8. Proportion of Cases: (i) Neither Parent has any Qualification, and (ii) Both Parents have Degree-level Qualifications, by Parental Class

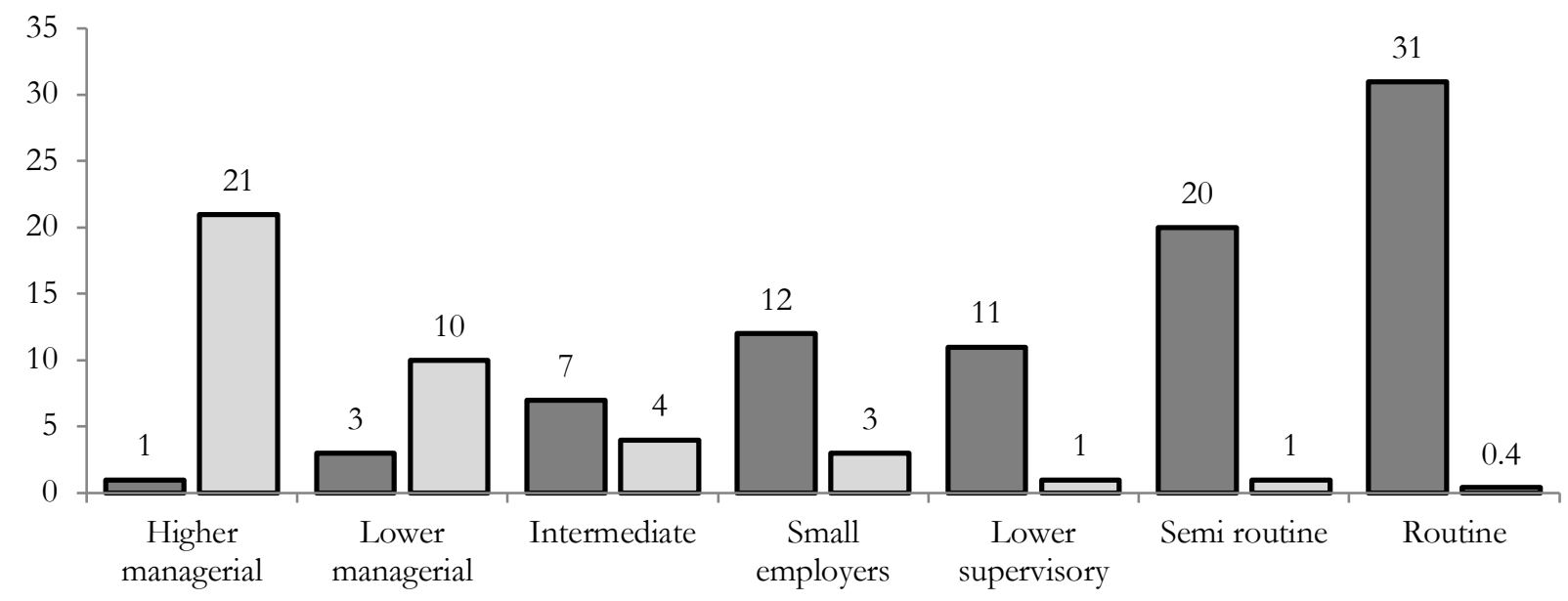

口Neither parent has any qualifications

口Both parents have degree-level qualifications

Figure 9 shows how the parental status variable is distributed within each of the seven groups of the categorical parental education variable.

Figure 9. Boxplot Distribution of Parental CG Status Scores (Original Scale) by Parental Education (Combined Approach 2)

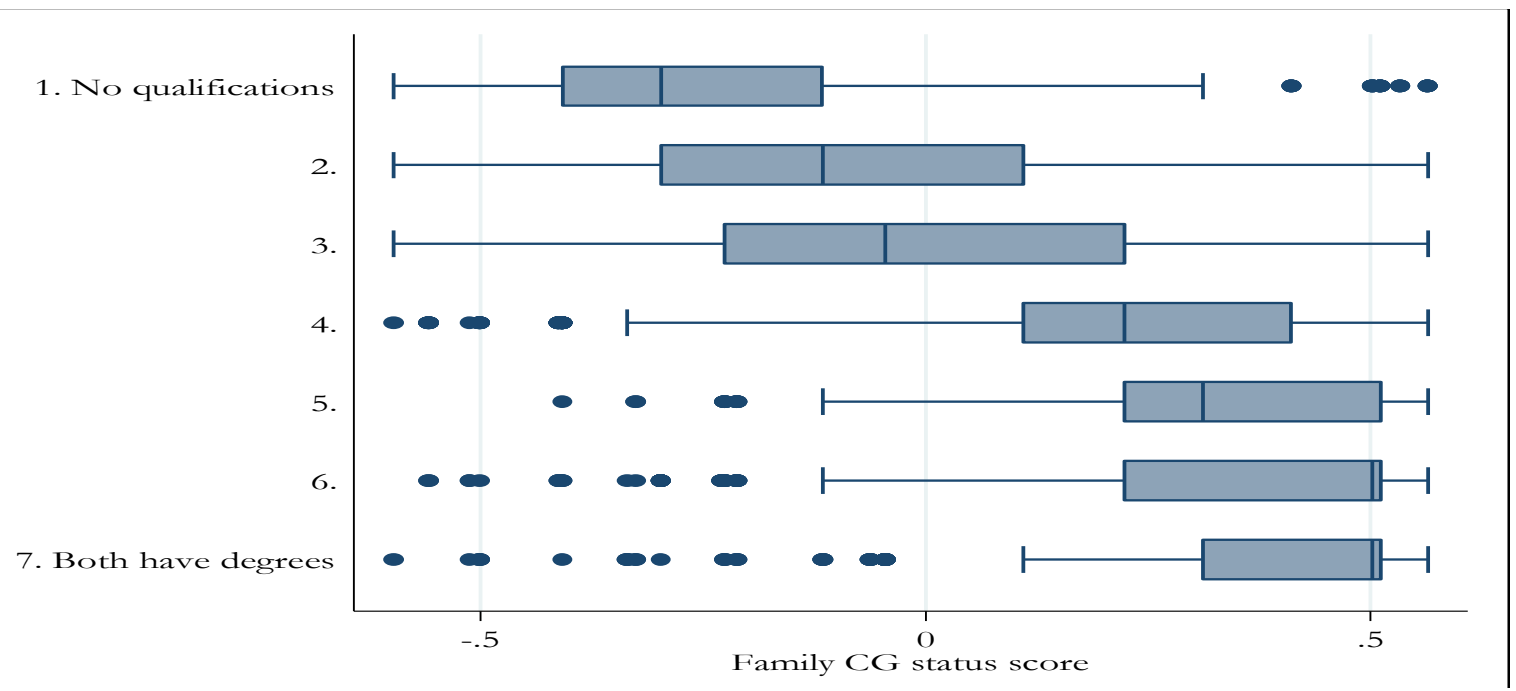

Notes: Graph uses wave 7 probability weight provided in the LSYPE dataset: W7_lsype_wt_skip

Table 16 uses the CG status quartiles variable to explore the relationship between parental status and parental education. 
Table 16. Cross-tabulation of CG Parental Status Quartiles and Parental Education (Combined Approach 2)

\begin{tabular}{|c|c|c|c|c|c|c|c|c|c|}
\hline & \multicolumn{8}{|c|}{ Parental education } \\
\hline & & $\begin{array}{c}\text { 1. No } \\
\text { qualifications }\end{array}$ & 2. & 3. & 4. & 5. & 6. & $\begin{array}{c}\text { 7. Both have } \\
\text { degrees }\end{array}$ & Total \\
\hline \multirow{15}{*}{ 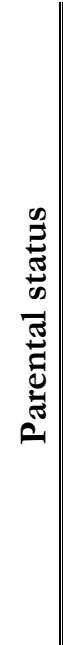 } & \multirow[t]{3}{*}{ Lowest } & 658 & 418 & 754 & 152 & 13 & 42 & 18 & 2055 \\
\hline & & $24 \%$ & $19 \%$ & $46 \%$ & $7 \%$ & $1 \%$ & $2 \%$ & $1 \%$ & $100 \%$ \\
\hline & & $65 \%$ & $48 \%$ & $33 \%$ & $11 \%$ & $5 \%$ & $4 \%$ & $2 \%$ & $27 \%$ \\
\hline & \multirow[t]{3}{*}{$2^{\text {nd }}$ Quartile } & 236 & 291 & 922 & 389 & 43 & 117 & 42 & 2040 \\
\hline & & $10 \%$ & $14 \%$ & $49 \%$ & 19 & $1 \%$ & $5 \%$ & $1 \%$ & $100 \%$ \\
\hline & & $26 \%$ & $35 \%$ & $35 \%$ & 28 & $11 \%$ & $12 \%$ & $7 \%$ & $28 \%$ \\
\hline & \multirow[t]{3}{*}{$3^{\text {rd }}$ Quartile } & 54 & 122 & 560 & 523 & 130 & 254 & 132 & 1775 \\
\hline & & $3 \%$ & $7 \%$ & $35 \%$ & 29 & $7 \%$ & $13 \%$ & $6 \%$ & $100 \%$ \\
\hline & & $6 \%$ & $14 \%$ & $21 \%$ & 35 & $39 \%$ & $28 \%$ & $21 \%$ & $23 \%$ \\
\hline & \multirow[t]{3}{*}{ Highest } & 25 & 37 & 298 & 364 & 159 & 502 & 413 & 1798 \\
\hline & & $1 \%$ & $2 \%$ & $18 \%$ & 22 & $9 \%$ & $26 \%$ & $22 \%$ & $100 \%$ \\
\hline & & $3 \%$ & $3 \%$ & $11 \%$ & 26 & $45 \%$ & $56 \%$ & $70 \%$ & $22 \%$ \\
\hline & \multirow[t]{3}{*}{ Total } & 973 & 868 & 2534 & 1428 & 345 & 915 & 605 & 7668 \\
\hline & & $10 \%$ & $11 \%$ & $38 \%$ & 19 & $4 \%$ & $11 \%$ & $7 \%$ & $100 \%$ \\
\hline & & $100 \%$ & $100 \%$ & $100 \%$ & 100 & $100 \%$ & $100 \%$ & $100 \%$ & $100 \%$ \\
\hline
\end{tabular}

Table 17 gives the mean, median and standard deviations of parental income by each category of parental class, status and education.

Table 17. Parental Income by Parental Class, CG Status Quartiles and Education (Combined Approach 2)

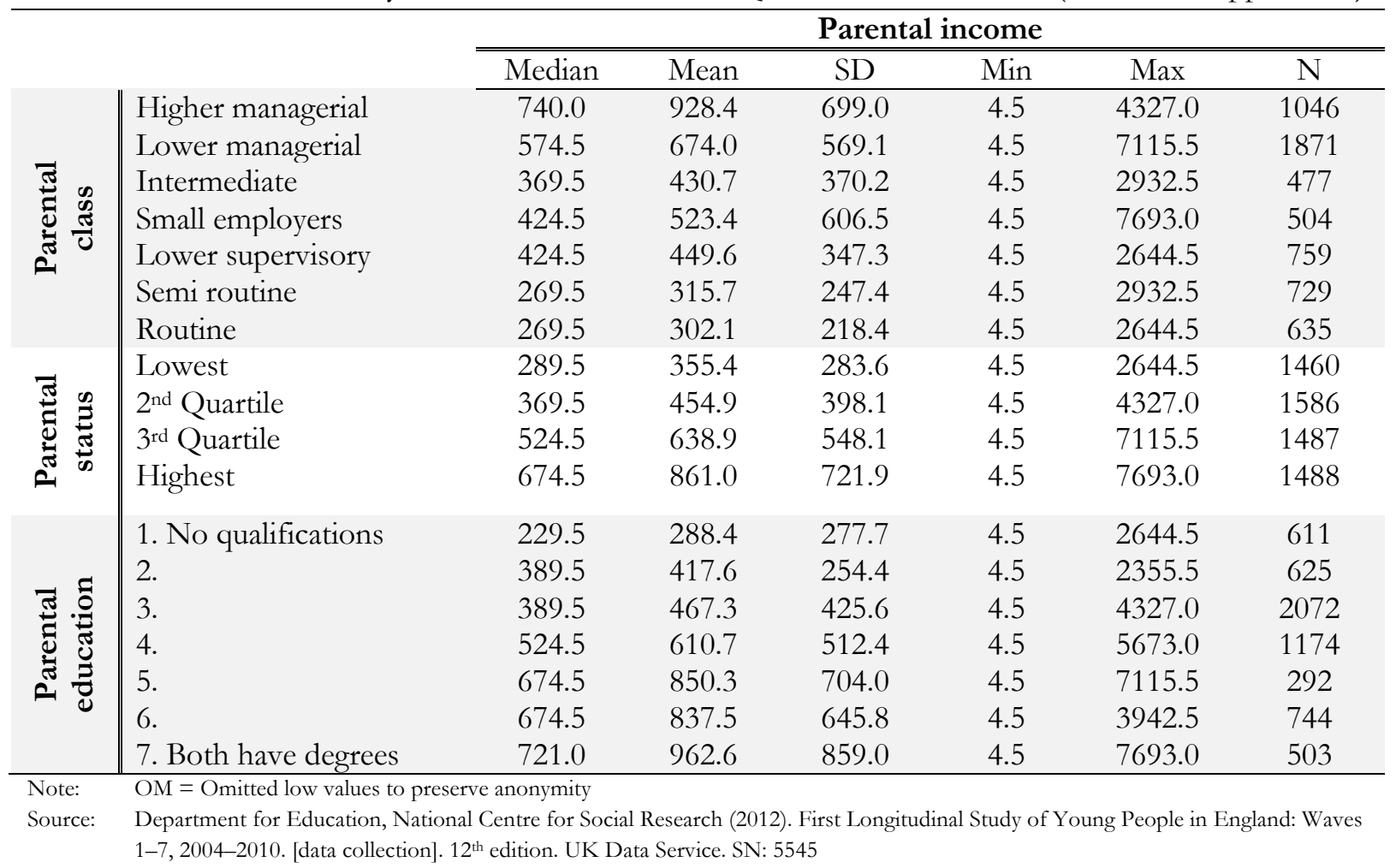

Finally, correlations between the social origin variables are presented below. Table 18 gives Spearman rank correlations between categorical measures and Table 19 gives Pearson correlations between alternative social origin measures, all of which have been normalised to take values in the range $0-1$. The strength of associations is largely similar across the two tables. All correlations are statistically significant $(\mathrm{p}<0.01)$. Parental class and status are strongly correlated, correlations between parental education and class or status are moderate, and correlations between parental income and any other social origin measure are weak. 
Table 18. Spearman Rank Correlations: Parental Class, CG Status Quartiles, Education (Combined Approach 2) and Income Quartiles

\begin{tabular}{lllll}
\hline & Class & Education & Status & Income \\
\cline { 2 - 5 } Class & 1.00 & & & \\
Education & $0.57^{* *}$ & 1.00 & & \\
Status & $0.71^{* *}$ & $0.60^{* *}$ & 1.00 & 1.00 \\
Income & $0.43^{* *}$ & $0.38^{* *}$ & $0.40^{* *}$ & \\
\hline Notes: Weights are not permitted with the Spearman command in Stata & &
\end{tabular}

Table 19. Pearson Correlations: Parental Class, CG Status (Original Scale), Education (Combined Approach 2 and Relative Scale) and Income (Original Scale)

\begin{tabular}{|c|c|c|c|c|c|}
\hline & Class & Education $\dagger$ & Education $\ddagger$ & Status & Income \\
\hline Class & $\overline{c 1.00}$ & & & & \\
\hline Education & $0.55^{* *}$ & 1.00 & & & \\
\hline Education & $0.53^{* *}$ & $0.94 * *$ & 1.00 & & \\
\hline Status & $0.71 * *$ & $0.59 * *$ & $0.58 * *$ & 1.00 & \\
\hline Income & $0.36^{* *}$ & $0.36 * *$ & $0.35^{* *}$ & $0.34 * *$ & 1.00 \\
\hline
\end{tabular}

\section{$8 \quad$ Educational Attainment}

This section provides an overview of the measures of respondents' educational attainment that will be used in the analysis for the research project. The latest information on educational attainment in the LSYPE is available for the year 2009/10, when respondents were aged 19-20 years old. Information on the highest qualification achieved by that age is taken from the NPD.

Table 20 describes how respondents are distributed across our defined levels of educational attainment. $39 \%$ of respondents achieved two or more A-levels, and only $2 \%$ had no formal qualifications at all.

Table 20. Highest Educational Qualification at age 19-20

\begin{tabular}{lcc}
\hline & & $\mathbf{N}$ \\
\cline { 2 - 3 } 1. No qualifications & 2.29 & 91 \\
2. Below O-level, NVQ1 & 14.78 & 775 \\
3. 1 - 4 O-level passes, NVQ2 & 15.83 & 943 \\
4. 5+ O-level passes or 1 A-level pass, NVQ3 & 28.18 & 2187 \\
5. 2+ A-level passes & 38.92 & 3672 \\
Total & 100.00 & 7668 \\
\hline
\end{tabular}

We also seek to analyse educational attainment according to whether respondents made various educational transitions at two crucial branching points: the first is at the end of compulsory education (after pupils sit GCSE exams), when respondents must decide whether to continue with further education (Key Stage 5), and then, conditional upon completion of study at Key Stage 5, the second transition we consider is whether respondents continue to higher education.

The measures of whether respondents made the transition to Key Stage 5 are based on both information in the NPD on exams taken (both successfully and unsuccessfully) at each level and on the information contained in the LSYPE questionnaires. See Table 21, which presents the distribution of two measures: whether respondents continued to Key Stage 5 study at all, and whether respondents continued to Key Stage 5 specifically to undertake further academic study (typically in the form of A-levels). 


\begin{tabular}{lcccccc}
\hline & \multicolumn{2}{c}{ Academic only } & & \multicolumn{2}{c}{ Academic and vocational } \\
\cline { 2 - 3 } \cline { 5 - 6 } \cline { 5 - 6 } No & $\%$ & $\mathrm{~N}$ & & $\%$ & \\
Yes & 46.06 & 2,749 & & 36.31 & 1,976 \\
Total & 53.94 & 4,919 & & 63.69 & 5,692 \\
\hline
\end{tabular}

Table 22 is presented for the purposes of describing the frequency with which respondents make the transition to further academic study but fail to complete the course. There are few instances in which pupils who begin their course of study do not sit the relevant exam, indicative of a low drop-out rate.

Table 22. Transition to Key Stage 5 (Academic), Participation v Sitting Exam

Did not enter KS5

Started AS level but did not sit exam

Took AS level exam

Total

\begin{tabular}{cc}
$\mathbf{\%}$ & $\mathbf{N}$ \\
\hline \hline 46.06 & 2,749 \\
5.70 & 470 \\
48.24 & 4,449 \\
100.00 & 7,668 \\
\hline
\end{tabular}

Tables 23 and 24 cross-tabulate the Key Stage 5 transition measures with respondents' highest level of qualification, in order to confirm the reliability of the measures. Table 23 considers only those who chose to pursue an academic course of study, while Table 24 considers both these pupils and those who chose to pursue a vocational route.

Table 23. Highest Educational Qualification Age 19-20 by Transition to KS5 (Academic)

\begin{tabular}{|c|c|c|c|}
\hline & \multicolumn{3}{|c|}{ KS5 Transition (academic only) } \\
\hline & No & Yes & Total \\
\hline \multirow{3}{*}{ 1. No qualifications } & 91 & & $\mathrm{OM}$ \\
\hline & $\mathrm{OM}$ & OM & $100.00 \%$ \\
\hline & $4.97 \%$ & & $2.29 \%$ \\
\hline \multirow[t]{3}{*}{ 2. Below O-level, NVQ1 } & 775 & & OM \\
\hline & OM & OM & $100.00 \%$ \\
\hline & $32.10 \%$ & & $14.78 \%$ \\
\hline \multirow[t]{3}{*}{ 3. 1-4 O-level passes, NVQ2 } & 766 & 177 & 943 \\
\hline & $85.84 \%$ & $14.16 \%$ & $100.00 \%$ \\
\hline & $29.49 \%$ & $4.16 \%$ & $15.83 \%$ \\
\hline \multirow[t]{3}{*}{ 4. 5+ O-level passes or 1 A-level pass, NVQ3 } & 1,117 & 1,070 & 2187 \\
\hline & $54.67 \%$ & $45.33 \%$ & $100.00 \%$ \\
\hline & $33.44 \%$ & $23.68 \%$ & $28.18 \%$ \\
\hline \multirow[t]{3}{*}{ 5. $2+$ A-level passes } & & 3,672 & OM \\
\hline & OM & $\mathrm{OM}$ & $100.00 \%$ \\
\hline & & $72.16 \%$ & $38.92 \%$ \\
\hline \multirow[t]{3}{*}{ Total } & 2,749 & 4,919 & 7668 \\
\hline & $46.06 \%$ & $53.94 \%$ & $100.00 \%$ \\
\hline & $100.00 \%$ & $100.00 \%$ & $100.00 \%$ \\
\hline
\end{tabular}

Some, though a small proportion (14\%), of pupils transitioned to further academic study at Key Stage 5 even though they had achieved fewer than five A*-C grade GCSEs. This number is slightly larger $(23 \%)$ when considering those who also transitioned to Key Stage 5 for a vocational course of study. 
Table 24. Highest Educational Qualification Age 19-20 by Transition to KS5 (Academic and Vocational)

\begin{tabular}{|c|c|c|c|}
\hline & KS5 Tran & academic & cational) \\
\hline & No & Yes & Total \\
\hline 1. No qualifications & 91 & & $\mathrm{OM}$ \\
\hline & OM & OM & $100.00 \%$ \\
\hline & $6.30 \%$ & & $2.29 \%$ \\
\hline 2. Below O-level, NVQ1 & 775 & & $\mathrm{OM}$ \\
\hline & $\mathrm{OM}$ & $\mathrm{OM}$ & $100.00 \%$ \\
\hline & $40.71 \%$ & & $14.78 \%$ \\
\hline 3. 1-4 O-level passes, NVQ2 & 664 & 279 & 943 \\
\hline & $77.39 \%$ & $22.61 \%$ & $100.00 \%$ \\
\hline & $33.73 \%$ & $5.62 \%$ & $15.83 \%$ \\
\hline 4. 5+ O-level passes or 1 A-level pass, NVQ3 & 446 & 1,741 & 2,187 \\
\hline & $24.82 \%$ & $75.18 \%$ & $100.00 \%$ \\
\hline & $19.26 \%$ & $33.26 \%$ & $28.18 \%$ \\
\hline 5. $2+$ A-level passes & & 3,672 & OM \\
\hline & $\mathrm{OM}$ & OM & $100.00 \%$ \\
\hline & & $61.12 \%$ & $38.92 \%$ \\
\hline Total & 1,976 & 5,692 & 7,668 \\
\hline & $36.31 \%$ & $63.69 \%$ & $100.00 \%$ \\
\hline & $100.00 \%$ & $100.00 \%$ & $100.00 \%$ \\
\hline
\end{tabular}

Note: $\quad \mathrm{OM}=$ Omitted low values to preserve anonymity

The descriptive statistics on whether respondents made the transition to higher education are based on variables contained in the LSYPE data at waves six and seven indicating whether the respondent was in higher education at the time of the interview. Tables 25 and 26 present the distribution of various transition to higher education measures. The majority of respondents do not transition to higher education by age 19-20. Among those that do, most pursue an academic rather than vocational option and most do not attend a high-prestige (defined as Russell Group) university.

Table 25. Transition to Higher Education and Type of Study

\begin{tabular}{lcc}
\hline & $\mathbf{\%}$ & $\mathbf{N}$ \\
\cline { 2 - 3 } No HE & 63.23 & 4,091 \\
Academic HE & 33.57 & 3,307 \\
Vocational HE & 3.16 & 265 \\
HE Type unknown & OM & OM \\
Missing & OM & OM \\
Total & 100.00 & 7,668 \\
\hline Note: OM = Omitted low values to preserve anonymity
\end{tabular}

Table 26. Transition to Higher Education and Prestige of Institution

\begin{tabular}{lcc}
\hline & $\mathbf{\%}$ & $\mathbf{N}$ \\
\cline { 2 - 3 } No HE & 63.23 & 4,091 \\
Non Russell-Group & 28.35 & 2,786 \\
Russell Group & 8.42 & 791 \\
Missing & & 0 \\
Total & 100.00 & 7,668 \\
\hline
\end{tabular}

In order to assess the reliability of the measures constructed, Tables 27 and 28 present cross-tabulations of the higher education transition variables with respondents' highest educational attainment. 
Table 27. Cross-tabulation of Highest Educational Qualification Age 19-20 by Transition to Higher Education

\begin{tabular}{lccc}
\hline \multirow{2}{*}{ 1. No qualifications } & No & Yes & Total \\
\cline { 2 - 4 } & 91 & & OM \\
2. Below O-level, NVQ1 & $\mathrm{OM}$ & $\mathrm{OM}$ & $100.00 \%$ \\
& $3.62 \%$ & & $2.29 \%$ \\
& 775 & & $\mathrm{OM}$ \\
3. 1-4 O-level passes, NVQ2 & $\mathrm{OM}$ & $\mathrm{OM}$ & $100.00 \%$ \\
& $23.38 \%$ & & $14.78 \%$ \\
& 894 & 49 & 943 \\
4. 5+ O-level passes or 1 A-level pass, NVQ3 & $96.37 \%$ & $3.63 \%$ & $100.00 \%$ \\
& $24.12 \%$ & $1.56 \%$ & $15.83 \%$ \\
5. 2+ A-level passes & 1,570 & 617 & 2,187 \\
& $76.84 \%$ & $23.16 \%$ & $100.00 \%$ \\
Total & $34.24 \%$ & $17.74 \%$ & $28.18 \%$ \\
& 761 & 2,911 & 3,672 \\
& $23.76 \%$ & $76.24 \%$ & $100.00 \%$ \\
& $14.63 \%$ & $80.70 \%$ & $38.92 \%$ \\
\hline
\end{tabular}

Table 28. Cross-tabulation of Highest Educational Qualification Age 19 - 20 by Transition to Higher Education (Prestige)

\begin{tabular}{|c|c|c|c|}
\hline & No HE & $\begin{array}{c}\text { Non } \\
\text { Russell }\end{array}$ & $\begin{array}{c}\text { Russell } \\
\text { Group }\end{array}$ \\
\hline \multirow{2}{*}{ 1. No qualifications } & 91 & & \\
\hline & $3.62 \%$ & OM & OM \\
\hline \multirow[t]{2}{*}{ 2. Below O-level, NVQ1 } & 775 & & \\
\hline & $23.38 \%$ & OM & OM \\
\hline \multirow{2}{*}{ 3. 1-4 O-level passes, NVQ2 } & 894 & 46 & \\
\hline & $24.12 \%$ & $1.94 \%$ & OM \\
\hline \multirow[t]{2}{*}{ 4. 5+ O-level passes or 1 A-level pass, NVQ3 } & 1,570 & 587 & 30 \\
\hline & $34.24 \%$ & $21.99 \%$ & $3.44 \%$ \\
\hline \multirow{2}{*}{ 5. $2+$ A-level passes } & 761 & 2,153 & 758 \\
\hline & $14.63 \%$ & $76.07 \%$ & $96.28 \%$ \\
\hline \multirow[t]{2}{*}{ Total } & 4,091 & 2,786 & 791 \\
\hline & $100.00 \%$ & $100.00 \%$ & $100.00 \%$ \\
\hline
\end{tabular}

Tables 29 and 30 cross-tabulate respondents' further and higher educational transitions. Of those who made the transition to further academic study at the end of compulsory education, $62 \%$ then also make the transition to higher education, implying that the majority of respondents use A-levels as their route into tertiary-level education. When also considering those who had transitioned to Key Stage 5 in order to pursue a vocational route of study, a lower proportion - 58\% - subsequently make the transition to higher education. 
Table 29. Transition to Key Stage 5 (Academic) by Transition to Higher Education

\begin{tabular}{l|lccc}
\hline \multirow{2}{*}{ No } & No & Yes & Total \\
\cline { 3 - 5 } & \multirow{2}{*}{ Yes } & 2,451 & 298 & 2,749 \\
& & $92.81 \%$ & $7.19 \%$ & $100.00 \%$ \\
& & $67.61 \%$ & $9.01 \%$ & $46.06 \%$ \\
& \multirow{2}{*}{ Total } & 1,640 & 3,279 & 4,919 \\
& & $37.97 \%$ & $62.03 \%$ & $100.00 \%$ \\
& & $32.39 \%$ & $90.99 \%$ & $53.94 \%$ \\
& & 4,091 & 3,577 & 7,668 \\
& & $63.23 \%$ & $36.77 \%$ & $100.00 \%$ \\
\hline
\end{tabular}

Table 30. Transition to Key Stage 5 (Academic and Vocational) by Transition to Higher Education

\begin{tabular}{l|lccc}
\hline \multirow{2}{*}{ No } & No & Yes & Total \\
\cline { 3 - 5 } & \multirow{3}{*}{ Yes } & 1,976 & 0 & 1,976 \\
& & $100.00 \%$ & $0.00 \%$ & $100.00 \%$ \\
& & $57.44 \%$ & $0.00 \%$ & $36.31 \%$ \\
& & 2,115 & 3,577 & 55,692 \\
& \multirow{2}{*}{ Total } & $42.26 \%$ & $57.74 \%$ & $100.00 \%$ \\
& & $42.56 \%$ & $100.00 \%$ & $63.69 \%$ \\
& & 4,091 & 3,577 & 7668 \\
\hline
\end{tabular}

Information on respondents' educational and occupational activity each year is given in the activity history files. This was supplemented with information from individual LSYPE waves and NPD data.

Table 31 summarises respondents' main activity, for the years 2006/09, 2007/08, 2008/09 and 2009/10.

Table 31. Detailed Activity by Academic Year

\section{GCSEs}

2. A/AS/Applied levels

3. NVQ 1-3

4. Apprenticeship/training

5. Higher education - non Russell

6. Higher education - Russell

7. Employed

8. Unemployed/Inactive (NEET)

9. Education - not specified

10. Insufficient information

Total

\begin{tabular}{lrrrr} 
& $\mathbf{2 0 0 6 / 0 7}$ & $\mathbf{2 0 0 7 / 0 8}$ & $\mathbf{2 0 0 8 / 0 9}$ & \multicolumn{2}{c}{$\mathbf{2 0 0 9 / 1 0}$} \\
\cline { 2 - 5 }$\%$ & 250 & 198 & 66 & 95 \\
$\mathrm{~N}$ & 3.17 & 2.42 & 0.86 & 1.01 \\
$\%$ & 4,495 & 4,125 & 644 & 101 \\
$\mathrm{~N}$ & 48.79 & 43.66 & 6.66 & 1.18 \\
$\%$ & 1,353 & 1,178 & 661 & 221 \\
$\mathrm{~N}$ & 18.38 & 15.92 & 8.59 & 3.03 \\
$\%$ & 269 & 399 & 391 & 324 \\
$\mathrm{~N}$ & 4.58 & 6.69 & 6.31 & 5.16 \\
$\%$ & 0 & 26 & 2,123 & 2,709 \\
$\mathrm{~N}$ & 0.00 & 0.32 & 21.36 & 27.54 \\
$\%$ & 0 & 0 & 609 & 761 \\
$\mathrm{~N}$ & 0.00 & 0.00 & 6.42 & 8.09 \\
$\%$ & 600 & 1,178 & 2,245 & 2,325 \\
$\mathrm{~N}$ & 11.98 & 20.82 & 34.90 & 36.03 \\
$\%$ & 298 & 340 & 811 & 838 \\
$\mathrm{~N}$ & 6.11 & 6.56 & 13.14 & 14.06 \\
$\%$ & 380 & 210 & 103 & 143 \\
$\mathrm{~N}$ & 6.48 & 3.31 & 1.48 & 1.75 \\
$\%$ & 23 & 14 & 15 & 151 \\
$\mathrm{~N}$ & 0.51 & 0.03 & 0.28 & 2.15 \\
$\%$ & 7,668 & 7,668 & 7,668 & 7,668 \\
$\%$ & 100 & 100 & 100 & 100 \\
\hline
\end{tabular}


Table 32 uses information from the latest available year - 2009/10 - in a cross-tabulation with respondents' highest educational attainment.

Table 32. Cross-tabulation of Detailed Activity and Highest Educational Attainment Age 19-20

\begin{tabular}{lccccc}
\hline & $\begin{array}{c}\text { 1. No } \\
\text { qualifications }\end{array}$ & 2. & 3. & 4. & $\begin{array}{c}5.2+\text { A- } \\
\text { level passes }\end{array}$ \\
\cline { 2 - 6 } [1] GCSEs & & & 22 & 28 & 20 \\
& $\mathrm{OM}$ & $\mathrm{OM}$ & $1.42 \%$ & $0.65 \%$ & $0.54 \%$ \\
[2] A/AS/Applied A & & & 25 & 46 & 20 \\
level & $\mathrm{OM}$ & $\mathrm{OM}$ & $1.82 \%$ & $1.99 \%$ & $0.56 \%$ \\
[3] NVQ 1-3 & 14 & 56 & 60 & 80 & 11 \\
& $17.15 \%$ & $5.89 \%$ & $5.11 \%$ & $3.24 \%$ & $0.30 \%$ \\
[4] Apprenticeship & & & 83 & 152 & 45 \\
/training & $\mathrm{OM}$ & $\mathrm{OM}$ & $9.79 \%$ & $7.51 \%$ & $1.55 \%$ \\
[5] Higher ed. - non- & & & 34 & 546 & 2,115 \\
Russell & $\mathrm{OM}$ & $\mathrm{OM}$ & $25.6 \%$ & $20.40 \%$ & $54.29 \%$ \\
[6] Higher ed. - & & & & 24 & 734 \\
Russell & $\mathrm{OM}$ & $\mathrm{OM}$ & $\mathrm{OM}$ & $0.81 \%$ & $20.14 \%$ \\
[7] Employed & 12 & 341 & 478 & 977 & 517 \\
[8] & $15.08 \%$ & $4.530 \%$ & $53.42 \%$ & $49.88 \%$ & $16.60 \%$ \\
Unemployed/Inactive & 50 & 260 & 190 & 228 & 110 \\
[9] Education - not & $54.54 \%$ & $34.97 \%$ & $20.69 \%$ & $11.02 \%$ & $3.25 \%$ \\
specified & & & 21 & 53 & 52 \\
[10] Insufficient & $\mathrm{OM}$ & $\mathrm{OM}$ & $1.87 \%$ & $2.22 \%$ & $1.30 \%$ \\
information & & & & 53 & 48 \\
Total & $\mathrm{OM}$ & $\mathrm{OM}$ & $\mathrm{OM}$ & $2.28 \%$ & $1.46 \%$ \\
& 91 & 775 & 943 & 2,187 & 3,672 \\
& $100.00 \%$ & $100.00 \%$ & $100.00 \%$ & $100.00 \%$ & $100.00 \%$ \\
\hline Note: OM = Omitted low values to preserve anonymity & & & &
\end{tabular}

Measures of performance at GCSE and Key Stage 5 were also constructed; distributions are presented in Tables 33-35 and Figures 10 and 11. The modal number of GCSEs graded A*-C (or equivalent) achieved is 10 and, among those who continued with further academic study at Key Stage 5, the modal number of A-levels (or equivalent) achieved is 3. 


\begin{tabular}{|c|c|c|}
\hline & $\%$ & $\mathbf{N}$ \\
\hline 0 & $17.73 \%$ & 918 \\
\hline 0.5 & $0.54 \%$ & 31 \\
\hline 1 & $5.93 \%$ & 366 \\
\hline 1.5 & $0.56 \%$ & 39 \\
\hline 2 & $4.06 \%$ & 260 \\
\hline 2.5 & $0.81 \%$ & 59 \\
\hline 3 & $3.14 \%$ & 223 \\
\hline 3.5 & $0.83 \%$ & 56 \\
\hline 4 & $4.65 \%$ & 311 \\
\hline 4.5 & $1.30 \%$ & 91 \\
\hline 5 & $3.45 \%$ & 274 \\
\hline 5.5 & $0.99 \%$ & 80 \\
\hline 6 & $3.42 \%$ & 304 \\
\hline 6.5 & $1.29 \%$ & 110 \\
\hline 7 & $3.96 \%$ & 333 \\
\hline 7.5 & $1.54 \%$ & 141 \\
\hline 8 & $4.87 \%$ & 414 \\
\hline 8.5 & $2.41 \%$ & 207 \\
\hline 9 & $6.43 \%$ & 538 \\
\hline 9.5 & $4.59 \%$ & 412 \\
\hline 10 & $9.35 \%$ & 809 \\
\hline 10.5 & $4.67 \%$ & 418 \\
\hline 11 & $5.57 \%$ & 515 \\
\hline 11.5 & $2.29 \%$ & 207 \\
\hline 12 & $1.95 \%$ & 196 \\
\hline 12.5 & $0.96 \%$ & 86 \\
\hline 13 & $1.03 \%$ & 99 \\
\hline 13.5 & $0.52 \%$ & 55 \\
\hline 14 & $0.46 \%$ & 49 \\
\hline 14.5 & $0.24 \%$ & 21 \\
\hline 15 & $0.29 \%$ & 23 \\
\hline 15.5 & OM & $\mathrm{OM}$ \\
\hline 16 & $\mathrm{OM}$ & $\mathrm{OM}$ \\
\hline 16.5 & OM & $\mathrm{OM}$ \\
\hline 17 & $\mathrm{OM}$ & $\mathrm{OM}$ \\
\hline 19 & OM & $\mathrm{OM}$ \\
\hline Missing & OM & $\mathrm{OM}$ \\
\hline Total & $100.00 \%$ & 7,668 \\
\hline
\end{tabular}


Table 34. Performance at Upper Secondary Level (Respondents who Transitioned to Academic KS5)

\begin{tabular}{ccc}
\hline & $\mathbf{\%}$ & $\mathbf{N}$ \\
\cline { 2 - 3 } 0 & $23.87 \%$ & 1,052 \\
1 & $3.96 \%$ & 195 \\
2 & $9.85 \%$ & 504 \\
3 & $36.17 \%$ & 1,887 \\
4 & $16.98 \%$ & 799 \\
5 & $2.81 \%$ & 143 \\
6 & $2.70 \%$ & 136 \\
7 & $0.74 \%$ & 41 \\
8 & $1.30 \%$ & 72 \\
9 & $0.73 \%$ & 43 \\
10 & $0.50 \%$ & 25 \\
11 & OM & OM \\
12 & OM & OM \\
13 & OM & OM \\
15 & OM & OM \\
16 & OM & OM \\
Total & $100.00 \%$ & 4,919 \\
\hline Note: & OM $=$ Omitted low values to preserve anonymity
\end{tabular}

Table 35. Performance at Upper Secondary Level (Full Sample)

\begin{tabular}{|c|c|c|}
\hline & $\%$ & $\mathbf{N}$ \\
\hline 0 & $58.94 \%$ & 3,801 \\
\hline 1 & $2.14 \%$ & 195 \\
\hline 2 & $5.31 \%$ & 504 \\
\hline 3 & $19.51 \%$ & 1,887 \\
\hline 4 & $9.16 \%$ & 799 \\
\hline 5 & $1.52 \%$ & 143 \\
\hline 6 & $1.45 \%$ & 136 \\
\hline 7 & $0.40 \%$ & 41 \\
\hline 8 & $0.70 \%$ & 72 \\
\hline 9 & $0.39 \%$ & 43 \\
\hline 10 & $0.27 \%$ & 25 \\
\hline 11 & OM & $\mathrm{OM}$ \\
\hline 12 & $\mathrm{OM}$ & $\mathrm{OM}$ \\
\hline 13 & $\mathrm{OM}$ & OM \\
\hline 15 & $\mathrm{OM}$ & $\mathrm{OM}$ \\
\hline 16 & OM & $\mathrm{OM}$ \\
\hline Total & $100.00 \%$ & 7,668 \\
\hline
\end{tabular}


Figure 10. Performance at Lower Secondary Level - Number of GCSE/GNVQ Qualifications at Grades A*-C

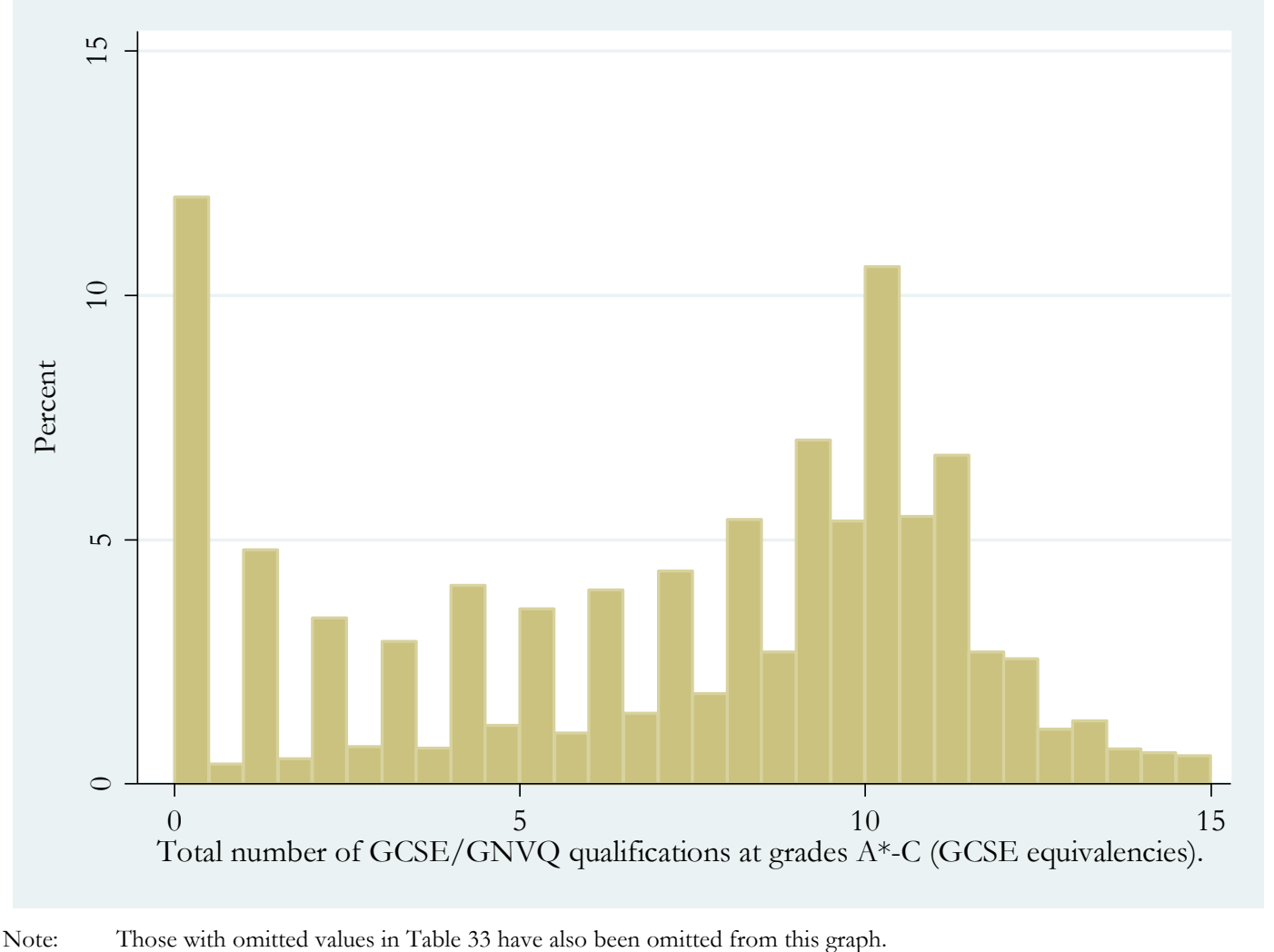

Figure 11. Performance at Upper Secondary Level (for Respondents who Made Transition to Key Stage 5) - Number of A-levels Passed

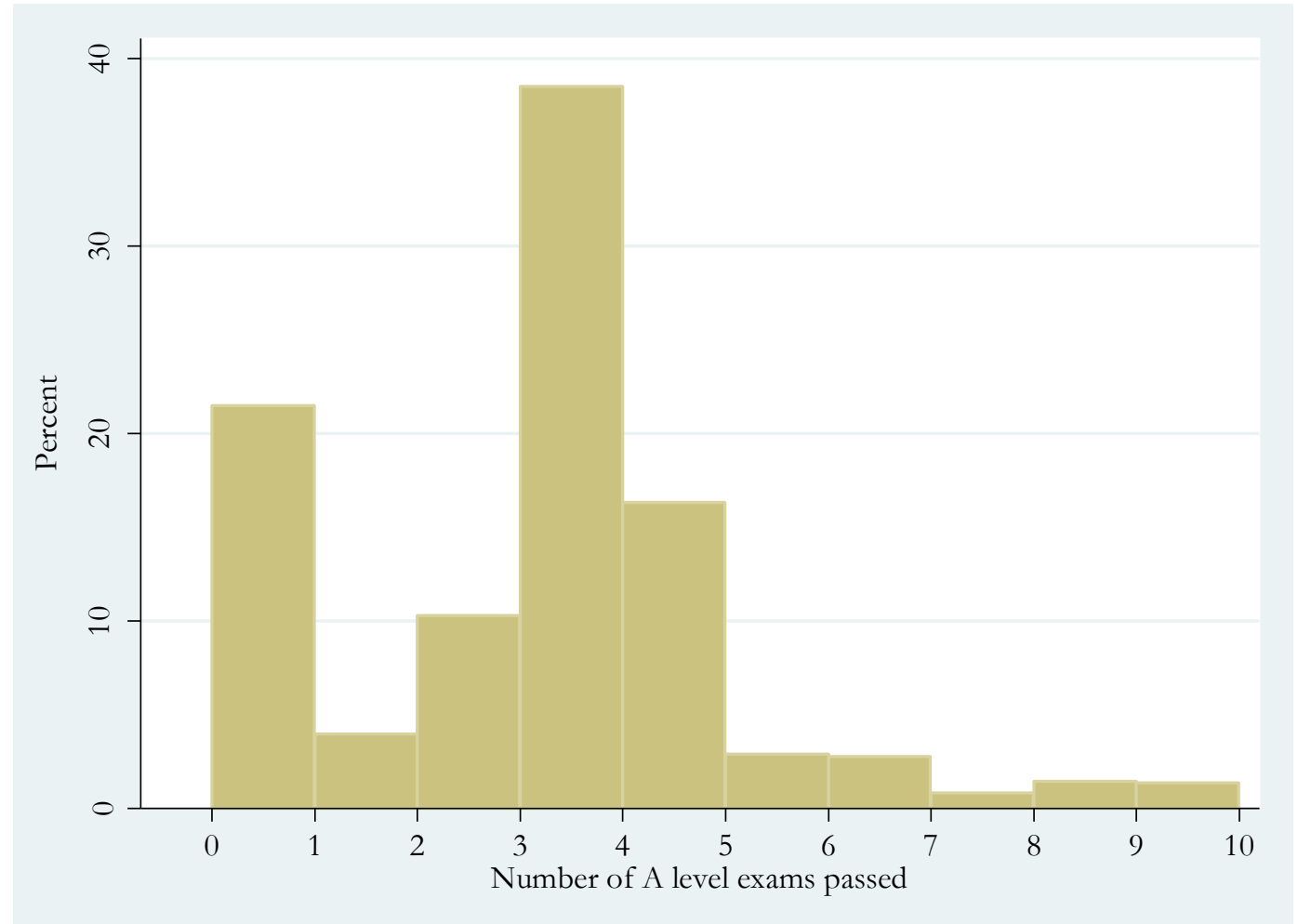

Note:

Those with omitted values in Table 34 have also been omitted from this graph. 


\section{Cognitive Ability}

Cognitive ability in the LSYPE is measured by scores achieved on national Key Stage 2 assessments, which pupils sit at age 11. This section describes the construction of two measures. The aim is to measure respondents' general intellectual capacity - otherwise termed ' $\mathrm{g}$ ' - by capturing the common variance across different tests. Fine-graded test scores are available for the English, maths and science components of the Key Stage 2 exams separately. Science scores are not useful for our purposes, because these tests are more content-specific than the general tests of verbal and non-verbal ability used to determine cognitive ability in the earlier birth cohorts. These are therefore excluded (with one exception - see below).

The first measure constructed uses English and maths scores in a principal components analysis (PCA), saving scores from the first factor extracted (generating the measure "KS2em"). The second measure uses an alternative approach for respondents who have zero scores (i.e. those who failed the tests). As the left diagram in Figure 12 shows, there are a notable proportion of these cases, leading to a 'spike' in the left tail of the histogram. The second measure therefore uses non-failed scores in place of failed scores for other Key Stage tests where possible. First, failed scores for maths are replaced with non-failed scores for English and vice versa. Then, of those who failed both, failed scores are replaced with non-failed science scores. Finally, those who failed all maths, English and science tests are set to missing. Scores on both measures are then included in a PCA (generating the measure "KS2emX2"). See Table 36. Figure 12 illustrates the distributions of the two measures.

Table 36. PCA to Derive Cognitive Ability Measures

\begin{tabular}{|c|c|c|c|c|c|c|c|c|}
\hline \multirow{4}{*}{ KS2em } & \multicolumn{4}{|c|}{ PCA } & \multicolumn{4}{|c|}{ New variables } \\
\hline & \multirow[t]{2}{*}{ Eigenvalue } & \multicolumn{2}{|c|}{ Loading } & \multirow[t]{2}{*}{$\%$ of variance } & \multirow[t]{2}{*}{ Min } & \multirow[t]{2}{*}{$\operatorname{Max}$} & \multirow[t]{2}{*}{ Mean (SD) } & \multirow[t]{2}{*}{ Valid N } \\
\hline & & English & Maths & & & & & \\
\hline & 1.75 & 0.71 & 0.71 & 0.87 & -3.93 & 2.83 & $0.00(1.32)$ & 7585 \\
\hline KS2emX2 & 1.72 & 0.71 & 0.71 & 0.86 & -3.64 & 3.03 & $0.00(1.31)$ & 7513 \\
\hline
\end{tabular}

Figure 12. Histogram of Cognitive Ability Measures
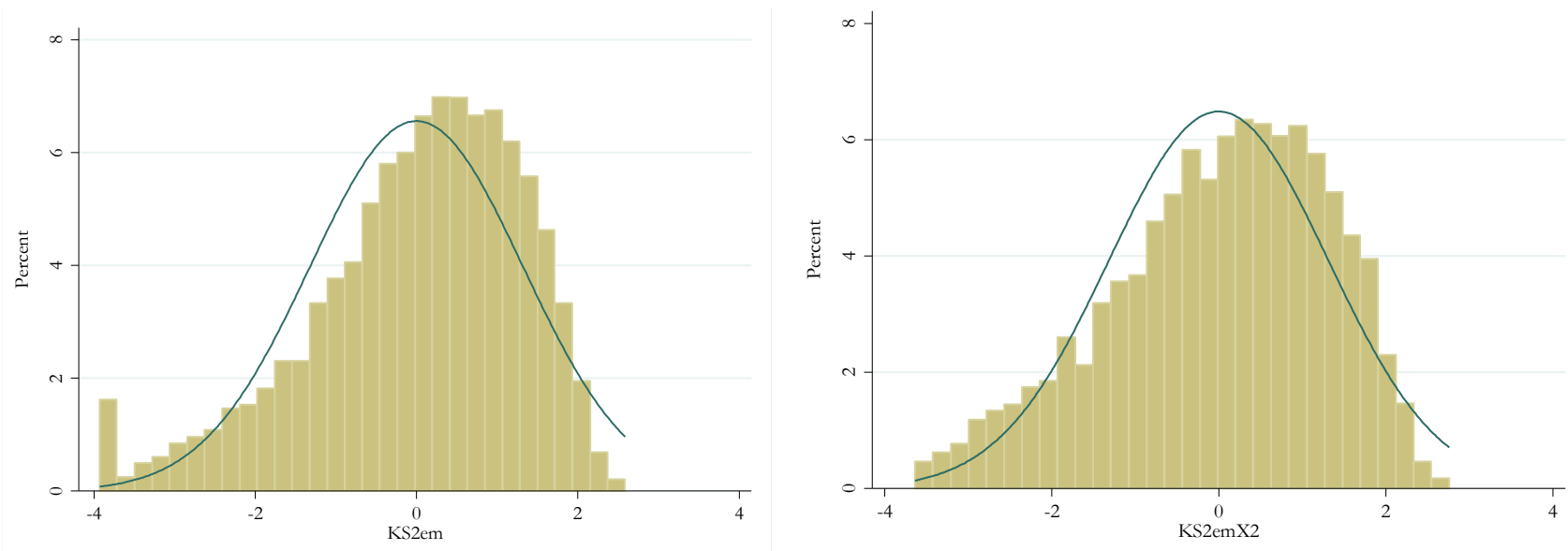

Note: A small number of cases with extremely high scores have been omitted from these graphs to preserve anonymity. KS2em N=7582; KS2emX2 N=7510.

\section{Social Origins and Cognitive Ability}

This section examines how cognitive ability is associated with each measure of social origin. Figures 13 and 14 and Table 37 describe how cognitive ability is distributed across social-class categories. On average, scores on tests of cognitive ability are higher among those from higher social-class groups, regardless of which measure of cognitive ability is used. 
Figure 13. Boxplot Distribution of Cognitive Ability (KS2em) by Parental Class

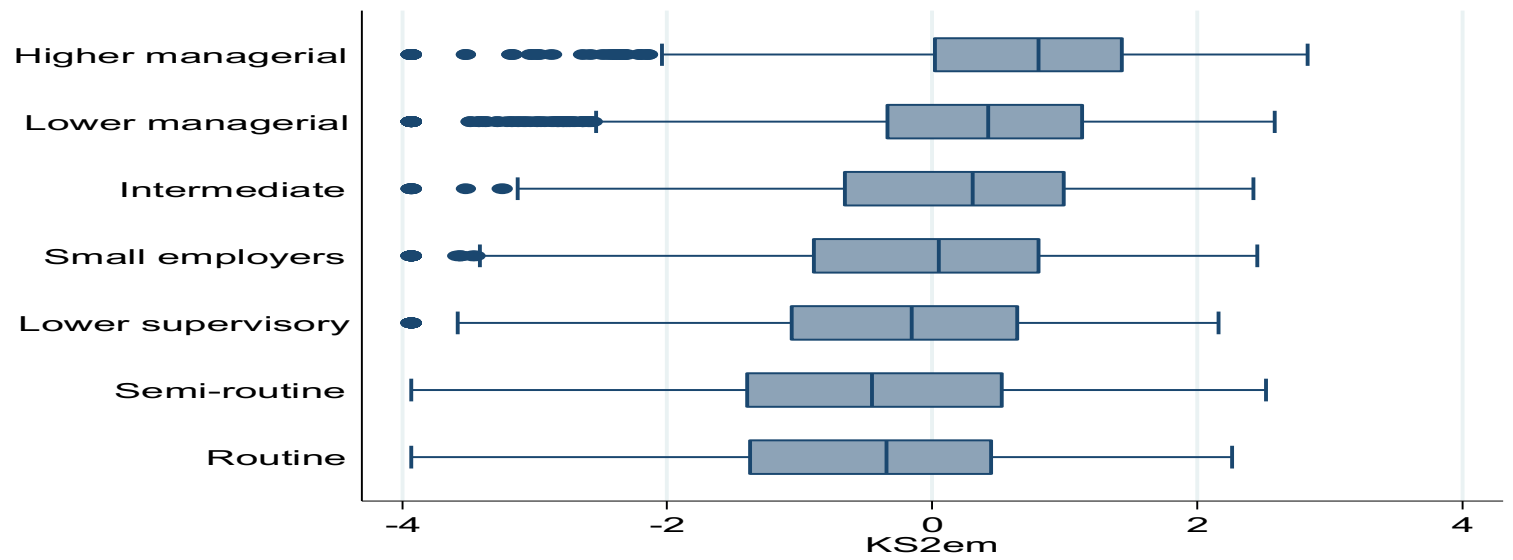

Figure 14. Boxplot Distribution of Cognitive Ability (KS2emX2) by Parental Class

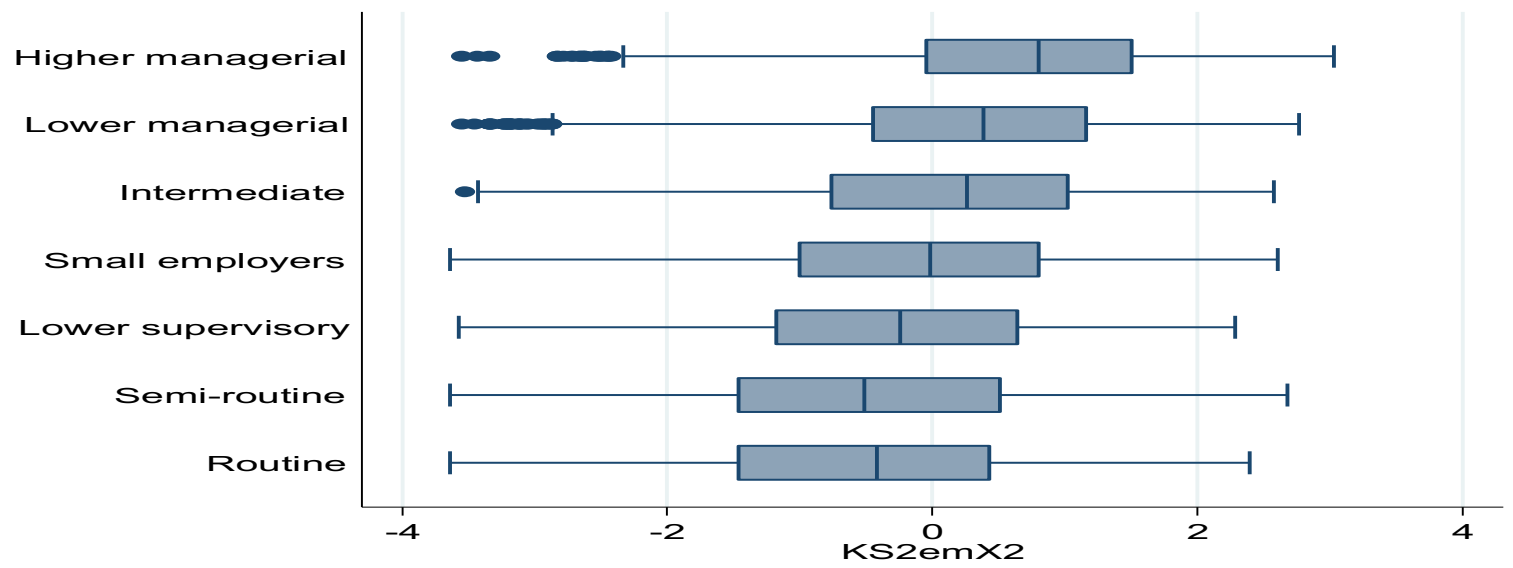

Table 37. Mean Cognitive Ability by Parental Class

\begin{tabular}{lcccccc}
\hline & \multicolumn{3}{c}{ KS2em } & \multicolumn{3}{c}{ KS2emX2 } \\
\cline { 2 - 7 } & Mean & SD & Freq. & Mean & SD & Freq. \\
\cline { 2 - 7 } Higher managerial & 0.54 & 1.17 & 1256 & 0.57 & 1.15 & 1249 \\
Lower managerial & 0.15 & 1.25 & 2243 & 0.15 & 1.24 & 2235 \\
Intermediate & -0.00 & 1.32 & 566 & -0.01 & 1.31 & 564 \\
Small employers & -0.25 & 1.33 & 741 & -0.26 & 1.31 & 734 \\
Lower supervisory & -0.44 & 1.29 & 953 & -0.45 & 1.26 & 945 \\
Semi-routine & -0.68 & 1.42 & 966 & -0.66 & 1.35 & 947 \\
Routine & -0.81 & 1.49 & 860 & -0.73 & 1.36 & 839 \\
\hline
\end{tabular}

Table 38 and Figures 15 and 16 provide similar summaries by quintiles of parental social status. The measures, in their original interval forms, are correlated at $0.35(\mathrm{p}<0.00)$ (using both KS2em and KS2emX2). Mean cognitive ability scores are higher among those whose parents have a higher social status.

Table 38. Mean Cognitive Ability by Parental Social Status Quintiles

\begin{tabular}{lcccccc}
\hline & \multicolumn{3}{c}{ KS2em } & \multicolumn{3}{c}{ KS2emX2 } \\
\cline { 2 - 7 } & Mean & SD & Freq. & Mean & SD & Freq. \\
\cline { 2 - 7 } Lowest & -0.82 & 1.47 & 1554 & -0.74 & 1.35 & 1513 \\
$2^{\text {nd }}$ Quintile & -0.49 & 1.35 & 1533 & -0.51 & 1.32 & 1517 \\
$3^{\text {rd }}$ Quintile & -0.03 & 1.26 & 1673 & -0.05 & 1.27 & 1667 \\
$4^{\text {th }}$ Quintile & 0.23 & 1.22 & 1307 & 0.23 & 1.22 & 1304 \\
Highest & 0.54 & 1.14 & 1518 & 0.56 & 1.14 & 1512 \\
\hline
\end{tabular}


Figure 15. Boxplot Distribution of Cognitive Ability (KS2em) by Parental Social Status Quintiles

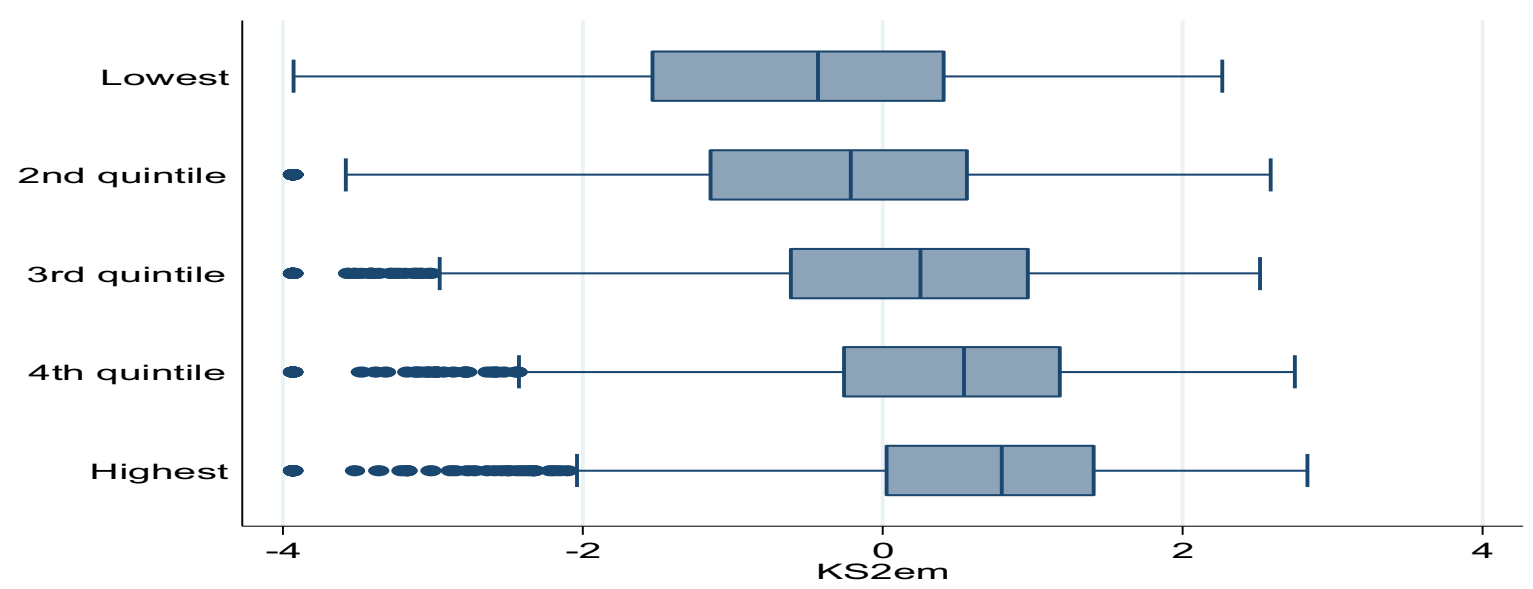

Figure 16. Boxplot Distribution of Cognitive Ability (KS2emX2) by Parental Social Status Quintiles

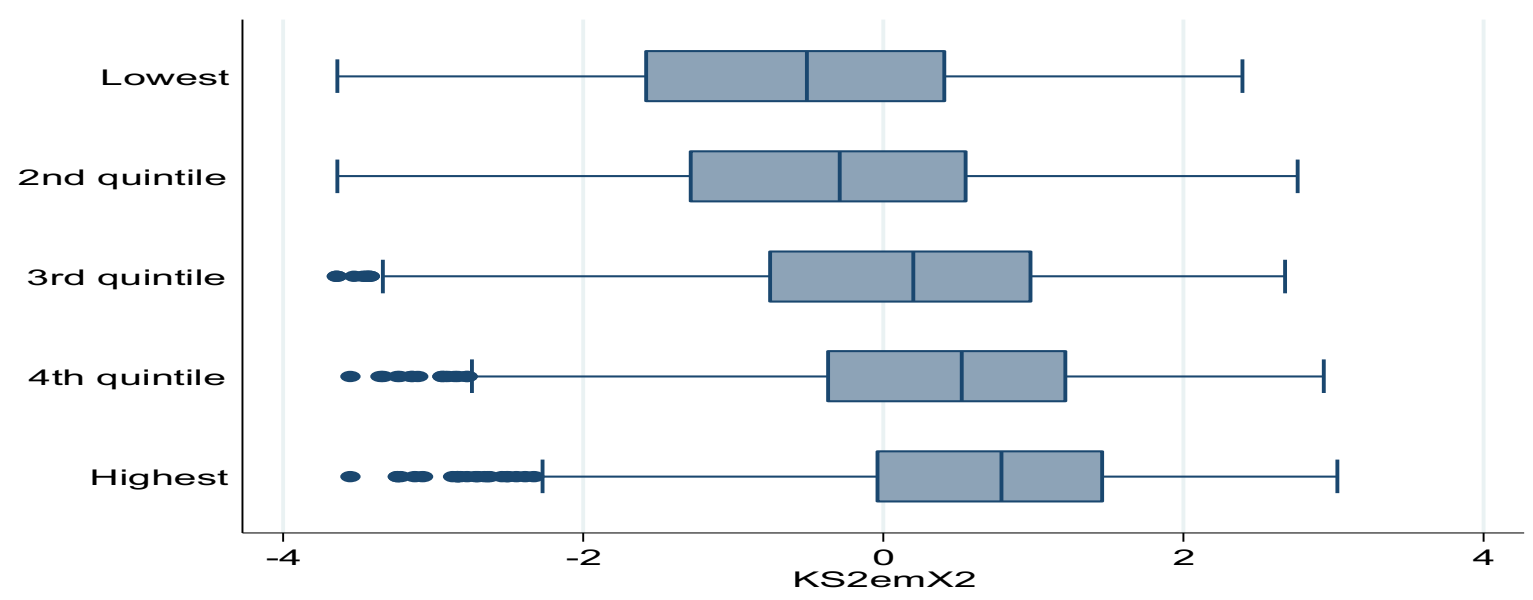

Table 39 examines the distribution of cognitive ability across categories of parental education.

Table 39. Mean Cognitive Ability by Parental Education

\begin{tabular}{lcccccc}
\hline & \multicolumn{3}{c}{ KS2em } & \multicolumn{3}{c}{ KS2emX2 } \\
\cline { 2 - 7 } 1. Neither parent has any qualification & Mean & SD & Freq. & Mean & SD & Freq. \\
\cline { 2 - 7 } 2. & -1.03 & 1.46 & 958 & -0.95 & 1.34 & 926 \\
3. & -0.70 & 1.44 & 856 & -0.65 & 1.32 & 843 \\
4. & -0.30 & 1.30 & 2510 & -0.32 & 1.28 & 2497 \\
5. & 0.06 & 1.27 & 1413 & 0.08 & 1.22 & 1403 \\
6. & 0.62 & 1.04 & 342 & 0.61 & 1.09 & 342 \\
7. Both parents have degrees & 0.61 & 1.04 & 905 & 0.62 & 1.06 & 902 \\
\hline
\end{tabular}

Table 40 presents the distribution of cognitive ability across parental income quintiles. The measures, in their original interval forms, are correlated at $0.23(\mathrm{p}<0.00)$ (using both KS2em and KS2emX2). 
Table 40. Mean Cognitive Ability by Parental Income

\begin{tabular}{lcccccc}
\hline & \multicolumn{3}{c}{ KS2em } & \multicolumn{3}{c}{ KS2emX2 } \\
\cline { 2 - 7 } & Mean & SD & Freq. & Mean & SD & Freq. \\
\cline { 2 - 7 } Lowest & -0.47 & 1.42 & 1291 & -0.46 & 1.38 & 1277 \\
$2^{\text {nd }}$ Quintile & -0.49 & 1.44 & 1096 & -0.46 & 1.38 & 1078 \\
3 $^{\text {rd }}$ Quintile & -0.22 & 1.37 & 1276 & -0.21 & 1.34 & 1267 \\
4 $^{\text {th }}$ Quintile & 0.12 & 1.23 & 1139 & 0.11 & 1.23 & 1134 \\
Highest & 0.53 & 1.08 & 1156 & 0.51 & 1.14 & 1156 \\
\hline
\end{tabular}

All of the foregoing suggests that, regardless of which measure of social origin is considered, mean cognitive ability scores are higher among those from more advantaged family backgrounds.

\section{Social Origins and Educational Attainment}

This section examines the relationship between each of the social origin measures and our educational attainment outcome variables.

Table 41 shows that higher levels of educational attainment are associated with higher social-class backgrounds. $65 \%$ of those from higher managerial and professional backgrounds, according to our scale, achieve the highest level of educational by age 19-20, compared with just $19 \%$ from routine backgrounds.

Table 41. Cross-tabulation of Parental Class by Young Person's Educational Attainment (\%)

\begin{tabular}{lccccc}
\hline & $\begin{array}{c}1 . \text { No } \\
\text { qualifications }\end{array}$ & 2. & 3. & 4. & $\begin{array}{c}5.2+\mathrm{A}- \\
\text { level passes }\end{array}$ \\
\cline { 2 - 6 } Higher managerial & & & 73 & 261 & 886 \\
Lower managerial & $\mathrm{OM}$ & $\mathrm{OM}$ & 7.75 & 12.73 & 26.58 \\
& 14 & 126 & 221 & 645 & 1258 \\
Intermediate & 16.49 & 16.33 & 23.47 & 30.51 & 35.50 \\
& & & 67 & 181 & 271 \\
Small employers & $\mathrm{OM}$ & $\mathrm{OM}$ & 7.53 & 8.11 & 7.37 \\
& & & 100 & 220 & 340 \\
Lower supervisory & $\mathrm{OM}$ & $\mathrm{OM}$ & 10.22 & 9.67 & 9.00 \\
& 11 & 147 & 166 & 318 & 324 \\
Semi-routine & 11.89 & 19.18 & 19.23 & 15.36 & 8.21 \\
& 16 & 169 & 165 & 307 & 323 \\
Routine & 18.13 & 21.32 & 16.88 & 13.50 & 7.73 \\
& 32 & 165 & 151 & 255 & 270 \\
Total & 35.05 & 22.81 & 14.91 & 10.11 & 5.62 \\
& 91 & 775 & 943 & 2187 & 3672 \\
Note: OM = Omitted low values to preserve anonymity & 100.00 & 100.00 & 100.00 \\
\hline
\end{tabular}

Table 42 considers academic transition measures. Those from higher social-class backgrounds are shown to continue on in post-compulsory education at rates substantially higher than their peers in lower socialclass categories. 
Table 42. Transition to KS5 (Academic) and HE by Social Class (\%)

\begin{tabular}{|c|c|c|c|c|}
\hline & \multicolumn{2}{|c|}{ KS5 (Academic) } & \multicolumn{2}{|c|}{$\mathrm{HE}$} \\
\hline & \%\% Transitioned & $\overline{\mathrm{N}}$ & \%\% Transitioned & $\overline{\mathrm{N}}$ \\
\hline Higher managerial & 76 & 1047 & 59 & 827 \\
\hline Lower managerial & 63 & 1594 & 45 & 1207 \\
\hline Intermediate & 55 & 377 & 37 & 272 \\
\hline Small employers & 54 & 474 & 33 & 332 \\
\hline Lower supervisory & 39 & 487 & 23 & 321 \\
\hline Semi-routine & 40 & 507 & 24 & 335 \\
\hline Routine & 33 & 873 & 19 & 283 \\
\hline
\end{tabular}

Tables 43 and 44 consider respondents' educational attainment by parents' education. Almost four times as many respondents achieve $2+$ A-levels among those whose parents both have degrees than among those whose parents have no qualifications. A similarly steep gradient is found for educational transitions.

Table 43. Cross-tabulation of Parental Education by Young Person's Educational Attainment

\begin{tabular}{|c|c|c|c|c|c|}
\hline & $\begin{array}{c}\text { 1. No } \\
\text { qualifications }\end{array}$ & 2. & 3. & 4. & $\begin{array}{l}5.2+\mathrm{A}- \\
\text { levels }\end{array}$ \\
\hline \multirow{2}{*}{ 1. No qualifications } & 26 & 193 & 154 & 257 & 343 \\
\hline & 28.81 & 21.76 & 12.46 & 8.16 & 5.21 \\
\hline \multirow[t]{2}{*}{2.} & 15 & 135 & 146 & 261 & 311 \\
\hline & 16.02 & 17.40 & 15.01 & 11.32 & 6.63 \\
\hline \multirow[t]{2}{*}{3.} & 31 & 327 & 392 & 878 & 906 \\
\hline & 37.07 & 45.99 & 45.89 & 44.46 & 27.40 \\
\hline \multirow[t]{2}{*}{4.} & 10 & 89 & 166 & 425 & 738 \\
\hline & 11.05 & 11.37 & 17.96 & 19.72 & 21.11 \\
\hline \multirow[t]{2}{*}{5.} & & & 21 & 83 & 233 \\
\hline & $\mathrm{OM}$ & $\mathrm{OM}$ & 2.41 & 3.92 & 7.08 \\
\hline \multirow[t]{2}{*}{6.} & & & 41 & 191 & 662 \\
\hline & $\mathrm{OM}$ & $\mathrm{OM}$ & 3.90 & 8.55 & 18.60 \\
\hline \multirow[t]{2}{*}{ 7. Both have degrees } & & & 23 & 92 & 479 \\
\hline & $\mathrm{OM}$ & $\mathrm{OM}$ & 2.37 & 3.88 & 13.96 \\
\hline \multirow[t]{2}{*}{ Total } & 91 & 775 & 943 & 2187 & 3672 \\
\hline & 100.00 & 100.00 & 100.00 & 100.00 & 100.00 \\
\hline
\end{tabular}

Table 44. Transition to KS5 (Academic) and HE by Parental Education (\%)

\begin{tabular}{|c|c|c|c|c|}
\hline \multirow{8}{*}{ 1. No qualifications } & \multicolumn{2}{|c|}{ KS5 (Academic) } & \multicolumn{2}{|c|}{$\mathrm{HE}$} \\
\hline & \% \% Transitioned & $\mathrm{N}$ & $\%$ Transitioned & $\mathrm{N}$ \\
\hline & 37 & 538 & 22 & 375 \\
\hline & 37 & 445 & 22 & 307 \\
\hline & 44 & 1359 & 26 & 871 \\
\hline & 61 & 984 & 41 & 711 \\
\hline & 77 & 282 & 58 & 220 \\
\hline & 81 & 774 & 65 & 633 \\
\hline 7. Both have degrees & 86 & 537 & 72 & 460 \\
\hline
\end{tabular}


Tables 45 and 46 consider parents' social status. Only $20 \%$ of those whose parents are in the lowest social status quintile achieve the highest level of educational qualification, compared to $65 \%$ of those in the highest quintile.

Table 45. Cross-tabulation of Parental Status Quintiles by Young Person's Educational Attainment (\%)

\begin{tabular}{|c|c|c|c|c|c|}
\hline & $\begin{array}{c}1 . \text { No } \\
\text { qualifications } \\
\end{array}$ & 2. & 3. & 4. & $\begin{array}{c}5.2+\mathrm{A}- \\
\text { level passes }\end{array}$ \\
\hline \multirow[t]{3}{*}{ Lowest } & 39 & 304 & 257 & 461 & 518 \\
\hline & 5.05 & 28.45 & 19.70 & 26.74 & 20.07 \\
\hline & 43.84 & 38.25 & 24.75 & 18.87 & 10.25 \\
\hline \multirow{3}{*}{$2^{\text {nd }}$ Quintile } & 23 & 227 & 270 & 504 & 530 \\
\hline & 2.61 & 20.11 & 22.23 & 30.20 & 24.84 \\
\hline & 25.00 & 29.77 & 30.73 & 23.46 & 13.97 \\
\hline \multirow[t]{3}{*}{$3^{\text {rd }}$ Quintile } & 14 & 142 & 210 & 527 & 795 \\
\hline & 1.63 & 12.06 & 15.99 & 30.92 & 39.41 \\
\hline & 15.92 & 18.22 & 22.56 & 24.51 & 22.61 \\
\hline \multirow[t]{3}{*}{$4^{\text {th }}$ Quintile } & & & 112 & 390 & 743 \\
\hline & OM & OM & 11.75 & 30.72 & 48.97 \\
\hline & & & 12.58 & 18.48 & 21.32 \\
\hline \multirow[t]{3}{*}{ Highest } & & & 94 & 305 & 1086 \\
\hline & OM & OM & 7.84 & 21.83 & 65.42 \\
\hline & & & 9.38 & 14.68 & 31.85 \\
\hline \multirow[t]{3}{*}{ Total } & 91 & 775 & 943 & 2187 & 3672 \\
\hline & 2.29 & 14.78 & 15.83 & 28.18 & 38.92 \\
\hline & 100.00 & 100.00 & 100.00 & 100.00 & 100.00 \\
\hline
\end{tabular}

Similarly, larger proportions of those whose parents are in higher status quintiles make the transition to further or higher education.

Table 46. Transition to KS5 (Academic) and HE by Parental Status Quintiles (\%)

\begin{tabular}{|c|c|c|c|c|}
\hline \multirow[b]{3}{*}{ Lowest } & \multicolumn{2}{|c|}{ KS5 (Academic) } & \multicolumn{2}{|c|}{ HE } \\
\hline & "\% Transitioned & $\overline{\mathrm{N}}$ & "\% Transitioned & $\overline{\mathrm{N}}$ \\
\hline & 34 & 801 & 19 & 526 \\
\hline $2^{\text {nd }}$ Quintile & 41 & 808 & 25 & 563 \\
\hline $3^{\text {rd }}$ Quintile & 56 & 1096 & 35 & 736 \\
\hline $4^{\text {th }}$ Quintile & 63 & 937 & 47 & 725 \\
\hline Highest & 78 & 1277 & 61 & 1027 \\
\hline
\end{tabular}

Finally, Tables 47 and 48 examine the association with parental income. A clear social gradient is found, both in relation to respondents' attainment and the likelihood of transitioning to further and higher academic education, however the relationship is not quite as strong as it is for other measures of social origin. $29 \%$ of those in the lowest income quintile achieve the highest educational qualification considered, and $28 \%$ of these pupils also undertake tertiary-level study. 
Table 47. Cross-tabulation of Parental Income Quintiles by Young Person's Educational Attainment (\%)

\begin{tabular}{lccccc}
\hline & $\begin{array}{c}\text { 1. No } \\
\text { Lualifications }\end{array}$ & 2. & 3. & 4. & $\begin{array}{c}5.2+\mathrm{A}- \\
\text { level passes }\end{array}$ \\
\cline { 2 - 6 } & 29 & 186 & 188 & 379 & 522 \\
& 4.35 & 22.57 & 17.21 & 26.43 & 29.43 \\
$2^{\text {nd }}$ Quintile & 41.27 & 32.83 & 23.33 & 20.57 & 16.33 \\
& 19 & 161 & 178 & 339 & 414 \\
& 3.05 & 20.39 & 20.86 & 28.95 & 26.76 \\
3rd Quintile & 24.55 & 25.15 & 23.99 & 19.11 & 12.60 \\
& 20 & 143 & 185 & 381 & 565 \\
& 3.01 & 15.60 & 18.30 & 28.74 & 34.35 \\
4th Quintile & 29.09 & 23.10 & 25.26 & 22.77 & 19.42 \\
& & & 125 & 363 & 577 \\
Highest & $\mathrm{OM}$ & $\mathrm{OM}$ & 14.86 & 32.03 & 42.37 \\
& & & 17.71 & 21.91 & 20.67 \\
Missing & & & 66 & 253 & 811 \\
Total & & $\mathrm{OM}$ & 8.22 & 23.05 & 64.03 \\
& 18 & 173 & 201 & 15.63 & 30.97 \\
& 91 & 775 & 943 & 2187 & 783 \\
& 2.28 & 14.89 & 15.98 & 27.83 & 3672 \\
& 100.00 & 100.00 & 100.00 & 100.00 & 100.00 \\
\hline
\end{tabular}

Table 48. Transition to KS5 (Academic) and HE by Parental Income Quintiles (\%)

\begin{tabular}{|c|c|c|c|c|}
\hline \multirow[b]{3}{*}{ Lowest } & \multicolumn{2}{|c|}{ KS5 (Academic) } & \multicolumn{2}{|c|}{$\mathrm{HE}$} \\
\hline & \% Transitioned & $\mathrm{N}$ & $\%$ Transitioned & $\mathrm{N}$ \\
\hline & 45 & 753 & 28 & 529 \\
\hline $2^{\text {nd }}$ Quintile & 42 & 613 & 27 & 438 \\
\hline $3^{\text {rd }}$ Quintile & 49 & 768 & 34 & 556 \\
\hline $4^{\text {th }}$ Quintile & 59 & 767 & 39 & 541 \\
\hline Highest & 77 & 957 & 59 & 759 \\
\hline Missing & & 1061 & & 754 \\
\hline
\end{tabular}

\section{Cognitive Ability and Educational Attainment}

This section will examine the association between cognitive ability, measured via scores attained on tests at Key Stage 2, and educational attainment later in life. Table 49 presents mean cognitive ability scores across categories of highest qualification achieved. Table 50 takes an alternative approach: mean scores are examined according to whether individuals passed various qualification thresholds. The first threshold compares those who attained some level of qualification (categories $2-5$ of the highest attainment variable) rather than none (category 1), the second threshold compares those who attained qualifications at NVQ 1 or higher (categories 3-8) with those whose attainment is lower (categories 1-2), and so on.

Table 49. Mean Cognitive Ability by Educational Attainment

\begin{tabular}{|c|c|c|c|c|}
\hline & \multicolumn{2}{|c|}{ KS2em } & \multicolumn{2}{|c|}{ KS2emX2 } \\
\hline & Mean (SD) & $\mathrm{N}$ & Mean (SD) & $\mathrm{N}$ \\
\hline 1. No qualifications & $-2.50(1.50)$ & 82 & $-1.84(1.28)$ & 56 \\
\hline 2. Below O-level, NVQ1 & $-1.75(1.23)$ & 752 & $-1.62(1.06)$ & 715 \\
\hline 3. 1-4 O-level passes, NVQ2 & $-0.77(1.05)$ & 928 & $-0.87(1.05)$ & 920 \\
\hline 4. 5+ O-level passes or 1 A-level pass, NVQ3 & $-0.05(0.97)$ & 2167 & $-0.13(1.04)$ & 2166 \\
\hline 5. $2+$ A-level passes & $0.79(0.88)$ & 3656 & $0.79(0.96)$ & 3656 \\
\hline
\end{tabular}


Table 50. Mean Cognitive Ability by Educational Attainment Thresholds at Age 20

\begin{tabular}{|c|c|c|c|c|}
\hline \multirow{3}{*}{ Threshold i. } & \multicolumn{2}{|c|}{ KS2em } & \multicolumn{2}{|c|}{ KS2emX2 } \\
\hline & Mean (SD) & $\mathrm{N}$ & Mean (SD) & $\mathrm{N}$ \\
\hline & & & & \\
\hline 1 & $-2.50(1.50)$ & 82 & $-1.85(1.28)$ & 56 \\
\hline $2-5$ & $-0.08(1.33)$ & 7503 & $-0.09(1.33)$ & 7457 \\
\hline Threshold ii. & & & & \\
\hline $1-2$ & $-1.84(1.29)$ & 834 & $-1.64(1.08)$ & 771 \\
\hline $3-5$ & $0.21(1.12)$ & 6751 & 0.17 (1.19) & 6742 \\
\hline Threshold iii. & & & & \\
\hline $1-3$ & $-1.32(1.30)$ & 1762 & $-1.25(1.14)$ & 1691 \\
\hline $4-5$ & $0.44(1.01)$ & 5823 & $0.40(1.09)$ & 5822 \\
\hline Threshold iv. & & & & \\
\hline $1-4$ & $-0.73(1.32)$ & 3929 & $-0.72(1.23)$ & 3857 \\
\hline 5 & $0.79(0.88)$ & 3656 & $0.79(0.96)$ & 3656 \\
\hline
\end{tabular}

A clear trend is identified which shows that higher cognitive ability is closely associated with higher levels of educational attainment. Table 51 examines mean cognitive ability by further and higher educational transitions, which again reveals a clear relationship.

Table 51. Mean Cognitive Ability by Educational Transitions

\begin{tabular}{|c|c|c|c|c|c|c|c|c|}
\hline & \multicolumn{4}{|c|}{ KS5 } & \multicolumn{4}{|c|}{$\mathrm{HE}$} \\
\hline & \multicolumn{2}{|c|}{ KS2em } & \multicolumn{2}{|c|}{ KS2emX2 } & \multicolumn{2}{|c|}{ KS2em } & \multicolumn{2}{|c|}{ KS2emX2 } \\
\hline & Mean (SD) & $\mathrm{N}$ & Mean (SD) & $\mathrm{N}$ & Mean (SD) & $\mathrm{N}$ & Mean (SD) & $\mathrm{N}$ \\
\hline No & $-0.92(1.34)$ & 2693 & $-0.89(1.23)$ & 2625 & $-0.62(1.37)$ & 4022 & $-0.59(1.28)$ & 3952 \\
\hline Yes & $0.53(1.01)$ & 4892 & $0.51(1.09)$ & 4888 & $0.68(0.96)$ & 3563 & $0.67(1.04)$ & 3561 \\
\hline
\end{tabular}




\section{Appendix}

Table A1. Details on Recoding of Original Parental Education Variables to Bukodi and Goldthorpe (2013) Scale

\begin{tabular}{|c|c|}
\hline Categories of original variable & Recoded to Bukodi and Goldthorpe (2013) scale \\
\hline $\begin{array}{l}\text {-99. Parent not interviewed } \\
-91 \text {. Not applicable - YP in care }\end{array}$ & Missing \\
\hline 1. Higher degree & 8. Higher degree, NVQ 6 [higher tertiary] \\
\hline 2. First degree & 7. Degree, NVQ 5 [higher tertiary] \\
\hline $\begin{array}{l}\text { 3. HE diploma } \\
\text { 4. HNC/HND/NVQ } 4 \\
\text { 5. Teaching qualification, non-degree } \\
\text { 6. Nursing qualification, non-degree }\end{array}$ & $\begin{array}{l}\text { 6. Tertiary sub-degree qualification, NVQ } 4 \text { [lower } \\
\text { tertiary] }\end{array}$ \\
\hline 7. A-levels & 5. 2+ A-level passes [higher secondary] \\
\hline $\begin{array}{l}\text { 8. OND/ONC } \\
\text { 9. City and Guilds part III, NVQ } 3\end{array}$ & $\begin{array}{l}\text { 4. 5+ O-level passes or } 1 \text { A-level pass, NVQ } 3 \text { [secondary } \\
\text { - high performance] }\end{array}$ \\
\hline 10. CSYS & 5.2+ A-level passes [higher secondary] \\
\hline $\begin{array}{l}\text { 11. Scottish higher grade } \\
\text { 12. AS level }\end{array}$ & $\begin{array}{l}\text { 4. 5+ O-level passes or } 1 \text { A-level pass, NVQ } 3 \text { [secondary } \\
\text { - high performance] }\end{array}$ \\
\hline $\begin{array}{l}\text { 13. Trade apprenticeship } \\
\text { 14. City and Guilds part II, NVQ } 2 \\
\text { 15. GCSE grades A-C and equivalent }\end{array}$ & $\begin{array}{l}\text { 3. 1-4 O-level passes, NVQ } 2 \text { [secondary - low } \\
\text { performance] }\end{array}$ \\
\hline $\begin{array}{l}\text { 16. GCSE grades D-E and equivalent } \\
\text { 17. City and Guilds part 1, NVQ } 1 \\
\text { 18. Youth training, skill seekers } \\
\text { 19. Qualification, level unspecified }\end{array}$ & 2. Below O-level, NVQ 1 [sub-secondary] \\
\hline
\end{tabular}

Table A2. Cross-tabulation between Parental Social Class and Parental Education (Combined Approach 2)

\begin{tabular}{|c|c|c|c|c|c|c|c|c|c|}
\hline & & & & & Parenta & educa & & & \\
\hline & & $\begin{array}{c}\text { 1. No } \\
\text { qualifications }\end{array}$ & 2. & 3. & 4. & 5. & 6. & $\begin{array}{c}\text { 7. Both have } \\
\text { degrees }\end{array}$ & Total \\
\hline & Higher managerial & 23 & 31 & 195 & 270 & 117 & 359 & 272 & 1267 \\
\hline & & $1 \%$ & $2 \%$ & $17 \%$ & $23 \%$ & $9 \%$ & $27 \%$ & $21 \%$ & $100 \%$ \\
\hline & & $2 \%$ & $3 \%$ & $7 \%$ & $20 \%$ & $34 \%$ & $41 \%$ & $46 \%$ & $16 \%$ \\
\hline & Lower managerial & 71 & 151 & 634 & 585 & 160 & 403 & 260 & 2264 \\
\hline & & $3 \%$ & $7 \%$ & $32 \%$ & $26 \%$ & $7 \%$ & $16 \%$ & $10 \%$ & $100 \%$ \\
\hline & & $8 \%$ & $18 \%$ & $24 \%$ & $40 \%$ & $47 \%$ & $43 \%$ & $42 \%$ & $29 \%$ \\
\hline & Intermediate & 35 & 47 & 277 & 133 & 22 & 35 & 23 & 572 \\
\hline & & $7 \%$ & $8 \%$ & $54 \%$ & $20 \%$ & $4 \%$ & $5 \%$ & $4 \%$ & $100 \%$ \\
\hline & & $5 \%$ & $5 \%$ & $10 \%$ & $8 \%$ & $6 \%$ & $3 \%$ & $4 \%$ & $7 \%$ \\
\hline & Small employers & 125 & 131 & 270 & 125 & 27 & 45 & 23 & 746 \\
\hline$\frac{\pi}{0}$ & & $12 \%$ & $17 \%$ & $43 \%$ & $16 \%$ & $3 \%$ & $5 \%$ & $3 \%$ & $100 \%$ \\
\hline$\frac{0}{\sigma}$ & & $11 \%$ & $15 \%$ & $11 \%$ & $8 \%$ & $7 \%$ & $5 \%$ & $4 \%$ & $9 \%$ \\
\hline$\ddot{ت}$ & Lower supervisory & 137 & 183 & 425 & 158 & 12 & 41 & 10 & 966 \\
\hline$\underset{\varpi}{\vec{\omega}}$ & & $11 \%$ & $18 \%$ & $49 \%$ & $17 \%$ & $1 \%$ & $4 \%$ & $1 \%$ & $100 \%$ \\
\hline 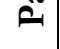 & & $14 \%$ & $22 \%$ & $18 \%$ & $12 \%$ & $4 \%$ & $5 \%$ & $1 \%$ & $14 \%$ \\
\hline & Semi routine & 249 & 172 & 422 & 94 & 5 & 26 & 12 & 980 \\
\hline & & $20 \%$ & $18 \%$ & $49 \%$ & $9 \%$ & $1 \%$ & $2 \%$ & $1 \%$ & $100 \%$ \\
\hline & & $26 \%$ & $21 \%$ & $17 \%$ & $7 \%$ & $2 \%$ & $2 \%$ & $2 \%$ & $13 \%$ \\
\hline & Routine & 333 & 153 & 311 & 63 & 2 & 6 & 5 & 873 \\
\hline & & $31 \%$ & $16 \%$ & $45 \%$ & $8 \%$ & $0.3 \%$ & $1 \%$ & $0.4 \%$ & $100 \%$ \\
\hline & & $35 \%$ & $16 \%$ & $14 \%$ & $5 \%$ & $1 \%$ & $1 \%$ & $1 \%$ & $12 \%$ \\
\hline & Total & 973 & 868 & 2534 & 1428 & 345 & 915 & 605 & 7668 \\
\hline & & $10 \%$ & $11 \%$ & $38 \%$ & $19 \%$ & $4 \%$ & $11 \%$ & $7 \%$ & $100 \%$ \\
\hline & & $100 \%$ & $100 \%$ & $100 \%$ & $100 \%$ & $100 \%$ & $100 \%$ & $100 \%$ & $100 \%$ \\
\hline
\end{tabular}

